\title{
Antiplatelet Drugs
}

\section{Antithrombotic Therapy and Prevention of Thrombosis, 9th ed: American College of Chest Physicians Evidence-Based Clinical Practice Guidelines}

\author{
John W. Eikelboom, MBBS; Jack Hirsh, MD, FCCP; Frederick A. Spencer, MD; \\ Trevor P. Baglin, MBChB, PhD; and Jeffrey I. Weitz, MD, FCCP
}

\begin{abstract}
The article describes the mechanisms of action, pharmacokinetics, and pharmacodynamics of aspirin, dipyridamole, cilostazol, the thienopyridines, and the glycoprotein IIb/IIIa antagonists. The relationships among dose, efficacy, and safety are discussed along with a mechanistic overview of results of randomized clinical trials. The article does not provide specific management recommendations but highlights important practical aspects of antiplatelet therapy, including optimal dosing, the variable balance between benefits and risks when antiplatelet therapies are used alone or in combination with other antiplatelet drugs in different clinical settings, and the implications of persistently high platelet reactivity despite such treatment.
\end{abstract}

CHEST 2012; 141(2)(Suppl):e89S-e119S

\begin{abstract}
Abbreviations: ACE $=$ angiotensin-converting enzyme; ACS = acute coronary syndrome; ACTIVE $=$ Atrial Fibrillation Clopidogrel Trial With Irbesartan for Prevention of Vascular Events; ADP = adenosine diphosphate; AMP = adenosine monophosphate; CAPRIE = Clopidogrel vs Aspirin in Patients at Risk for Ischemic Events; COMMIT = Clopidogrel and Metoprolol Myocardial Infarction Trial; COX = cyclooxygenase; CURE = Clopidogrel in Unstable Angina to Prevent Recurrent Events; CURRENT-OASIS 7 = Clopidogrel Optimal Loading Dose Usage to Reduce Recurrent Events/ Organization to Assess Strategies for Ischemic Syndromes; CYP450 = cytochrome P450; EPIC = Evaluation of 7E3 for the Prevention of Ischaemic Complications; ESPRIT = Aspirin Plus Dipyridamole Versus Aspirin Alone After Cerebral Ischaemia of Arterial Origin; ESPS = European Stroke Prevention Study; FDA = US Food and Drug Administration; GpIIb-IIIa = glycoprotein IIb/IIIa; HR = hazard ratio; IMPACT-II = Integrilin to Minimise Platelet Aggregation and Coronary Thrombosis-II; MI = myocardial infarction; NSAID = nonsteroidal antiinflammatory drug; PCI = percutaneous coronary intervention; $\mathrm{PGH}_{2}=$ prostaglandin $\mathrm{H}_{2} ; \mathrm{PGI}_{2}=$ prostacyclin; $\mathrm{PLATO}=$ Study of Platelet Inhibition and Patient Outcomes; PTCA = percutaneous transluminal coronary angioplasty; $\mathrm{RR}=$ rate ratio; TIA = transient ischemic attack; $\mathrm{TTP}=$ thrombotic thrombocytopenic purpura; $\mathrm{TXA}_{2}=$ thromboxane $\mathrm{A}_{2}$
\end{abstract}

$\mathbf{P}$

atelets are vital components of normal hemostasis and key participants in atherothrombosis by virtue of their capacity to adhere to the injured blood vessel wall; recruit additional platelets to the site of injury; release vasoactive and prothrombotic mediators that trigger vasoconstriction and promote coagulation, respectively; and form aggregates that affect primary hemostasis. ${ }^{1}$ Although platelet adhesion, activation, and aggregation can be viewed as a physiologic repair response to the sudden fissuring or rupture of an atherosclerotic plaque, uncontrolled progression of such a process through a series of self-sustaining amplification loops can lead to intraluminal thrombus formation, vascular occlusion, and subsequent ischemia or infarction. Currently available antiplatelet drugs interfere with one or more steps in the process of platelet release and aggregation ${ }^{2}$ and produce a measurable reduction in the risk of thrombosis that cannot be dissociated from an increased risk of bleeding. ${ }^{3}$

When considering antiplatelet drugs, it is important to appreciate that $\sim 10^{11}$ platelets are produced each day under physiologic circumstances, a level of production that can increase up to 10 -fold at times of increased need. ${ }^{4}$ Platelets are anucleated blood cells that form by fragmentation of bone marrow megakaryocyte cytoplasm and have a maximum circulating life span of $\sim 10$ days. Regulation of platelet production is mediated by thrombopoietin, which is produced primarily in the liver as well as in the bone marrow and the kidney and cleared by binding to 
high-affinity receptors on platelets and megakaryocytes. ${ }^{5}$ In the presence of a high-platelet mass, thrombopoietin levels are reduced, and platelet production falls, whereas in the presence of a low-platelet mass, thrombopoietin levels rise, thereby stimulating thrombopoiesis. Platelets provide a circulating source of chemokines, cytokines, and growth factors, which are preformed and packaged in storage granules. Activated platelets can synthesize prostanoids, primarily thromboxane $\mathrm{A}_{2}\left(\mathrm{TXA}_{2}\right)$, from arachidonic acid released from membrane phospholipids through rapid coordinated activation of phospholipases, cyclooxygenase (COX)-1, and TX synthase (Fig 1). The inducible form of COX (COX-2) not only is found primarily in the vascular endothelium and in monocytes but is also expressed in newly formed platelets, particularly in the setting of accelerated platelet production. ${ }^{6}$ Although activated platelets are incapable of de novo protein synthesis, they can translate constitutive mRNA into protein over the course of several hours. ${ }^{7}$ Thus, platelets may play a part in inflammation, angiogenesis, and wound healing, and antiplatelet therapies may have an impact on these processes by blocking platelet-derived protein signals for inflammatory or proliferative responses.

Negative modulation of platelet adhesion and aggregation is exerted by a variety of physiologic mechanisms, including endothelium-derived prostacyclin $\left(\mathrm{PGI}_{2}\right)$, nitric oxide, CD39/ecto-ADPase, and platelet endothelial cell adhesion molecule-1. Some drugs may interfere with these regulatory pathways, as exemplified by the dose-dependent inhibition of $\mathrm{PGI}_{2}$ production by aspirin and other COX-1 and COX-2 inhibitors. ${ }^{3}$

Revision accepted August 31, 2011

Affiliations: From the Department of Medicine (Drs Eikelboom, Hirsh, Spencer, and Weitz), McMaster University; Population Health Research Institute (Drs Eikelboom and Hirsh); and Thrombosis and Atherosclerosis Research Institute (Drs Eikelboom, Hirsh, Spencer, and Weitz), Hamilton, ON, Canada; and Department of Haematology (Dr Baglin), Addenbrooke's NHS Trust, Cambridge, England. Funding/Support: The Antithrombotic Therapy and Prevention of Thrombosis, 9th ed: American College of Chest Physicians Evidence-Based Clinical Practice Guidelines received support from the National Heart, Lung, and Blood Institute [R13 HL104758] and Bayer Schering Pharma AG. Support in the form of educational grants was also provided by Bristol-Myers Squibb; Pfizer, Inc; Canyon Pharmaceuticals; and sanofi-aventis US.

Disclaimer: American College of Chest Physician guidelines are intended for general information only, are not medical advice, and do not replace professional medical care and physician advice, which always should be sought for any medical condition. The complete disclaimer for this guideline can be accessed at http:// chestjournal.chestpubs.org/content/141/2_suppl/1S.

Correspondence to: John W. Eikelboom, MBBS, McMaster University, Hamilton General Site, 237 Barton St E, Hamilton, ON, L9K 1H8, Canada; e-mail: eikelbj@mcmaster.ca

(C) 2012 American College of Chest Physicians. Reproduction of this article is prohibited without written permission from the American College of Chest Physicians (http://www.chestpubs.org/ site/misc/reprints.xhtml).

DOI: 10.1378/chest.11-2293
The article on antiplatelet therapy in the American College of Chest Physicians Evidence-Based Clinical Practice Guidelines (8th Edition) reviewed the antiplatelet effects of traditional nonsteroidal antiinflammatory drugs (NSAIDs) and the cardiovascular effects of COX-2-selective NSAIDs. This topic will not be covered here, and interested readers are referred to the previous article. ${ }^{8}$

\subsection{ASPIRIN}

Aspirin is the most widely studied antiplatelet drug. On the basis of $>100$ randomized trials in high-risk patients, aspirin reduces vascular death by $\sim 15 \%$ and nonfatal vascular events by $\sim 30 \%, 9,10$

\subsection{Mechanism of Action}

The best-characterized mechanism of action of aspirin is related to its capacity to permanently inhibit the COX activity of prostaglandin $\mathrm{H}$-synthase- 1 and prostaglandin H-synthase-2 (also referred to as COX-1 and COX-2, respectively). ${ }^{11-15}$ COX isozymes catalyze the first committed step in prostanoid biosynthesis, the conversion of arachidonic acid to prostaglandin $\mathrm{H}_{2}\left(\mathrm{PGH}_{2}\right)$ (Fig 1). $\mathrm{PGH}_{2}$ is the immediate precursor of $\mathrm{TXA}_{2}$ and $\mathrm{PGI}_{2}$.

The molecular mechanism of permanent inhibition of COX activity by aspirin is related to blockade of the COX channel as a consequence of acetylation of a strategically located serine residue (Ser529 in COX-1, Ser516 in COX-2), thereby preventing substrate access to the catalytic site of the enzyme. ${ }^{16}$ Complete or near-complete inhibition of platelet COX-1 can be achieved with low doses of aspirin (75-150 mg) given once daily. In contrast, inhibition of COX-2-dependent pathophysiologic processes (eg, hyperalgesia, inflammation) requires larger doses of aspirin and a much shorter dosing interval because nucleated cells rapidly resynthesize the enzyme. Thus, 10 - to 100 -fold higher daily doses of aspirin are required when the drug is used as an antiinflammatory agent rather than as an antiplatelet agent. The benefit/risk profile of aspirin depends on dose because its GI toxicity is dose dependent (discussed in section 1.3 "The Optimal Dose of Aspirin").

Human platelets and vascular endothelial cells process $\mathrm{PGH}_{2}$ to produce primarily $\mathrm{TXA}_{2}$ and $\mathrm{PGI}_{2}$, respectively.12 $\mathrm{TXA}_{2}$ induces platelet aggregation and vasoconstriction, whereas $\mathrm{PGI}_{2}$ inhibits platelet aggregation and induces vasodilation. ${ }^{12}$ Because TXA $_{2}$ is largely derived from COX-1 (mostly from platelets), it is highly sensitive to aspirin inhibition. In contrast, although vascular $\mathrm{PGI}_{2}$ can be derived from COX-1, its major source is COX-2, even under physiologic conditions. ${ }^{17} \mathrm{COX}$-1-dependent $\mathrm{PGI}_{2}$ production 


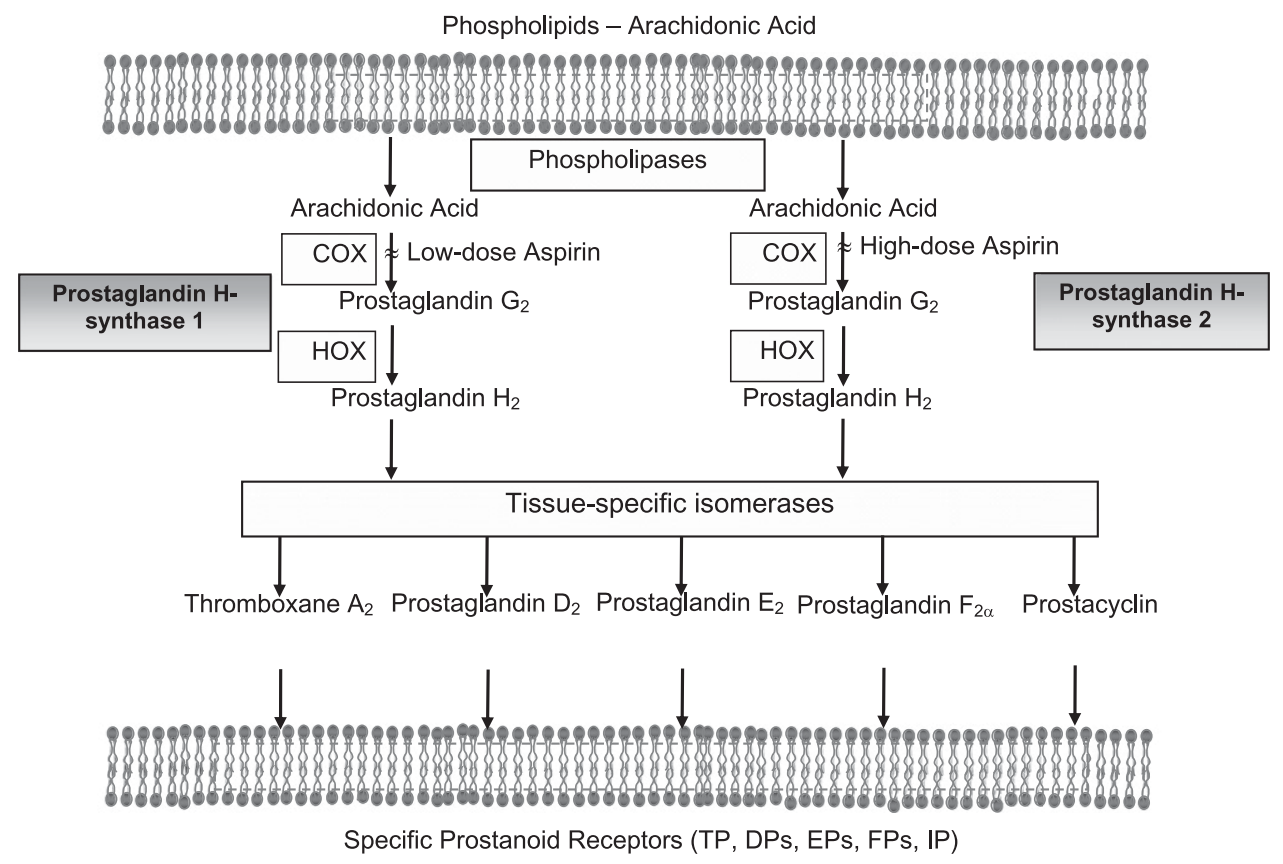

FIGURE 1. Arachidonic acid metabolism and mechanism of action of aspirin. Arachidonic acid, a 20 -carbon fatty acid containing four double bonds, is liberated from the sn2 position in membrane phospholipids by several forms of phospholipase, which are activated by diverse stimuli. Arachidonic acid is converted by cytosolic prostaglandin $\mathrm{H}$ synthases, which have both COX and HOX activity, to the unstable intermediate prostaglandin $\mathrm{H}_{2}$. The synthases are colloquially termed "cyclooxygenases" and exist in two forms, COX-1 and COX-2. Low-dose aspirin selectively inhibits COX-1, and highdose aspirin inhibits both COX-1 and COX-2. Prostaglandin $\mathrm{H}_{2}$ is converted by tissue-specific isomerases to multiple prostanoids. These bioactive lipids activate specific cell membrane receptors of the superfamily of G-protein-coupled receptors. $\mathrm{COX}=$ cyclooxygenase; $\mathrm{DP}=$ prostaglandin $\mathrm{D}_{2}$ receptor; $\mathrm{EP}=$ prostaglandin $\mathrm{E}_{2}$ receptor; $\mathrm{FP}=$ prostaglandin $\mathrm{F}_{2 \alpha}$ receptor; $\mathrm{HOX}=$ hydroperoxidase; $\mathrm{IP}=$ prostacyclin receptor; $\mathrm{TP}=$ thromboxane receptor.

occurs transiently in response to agonist stimulation (eg, bradykinin $)^{18}$ and is sensitive to aspirin inhibition. COX-2-mediated $\mathrm{PGI}_{2}$ production occurs long term in response to laminar shear stress ${ }^{19}$ and is relatively insensitive to low-dose aspirin, which may explain the substantial residual COX-2-dependent PGI biosynthesis that occurs with daily doses of aspirin in the range of 30 to $100 \mathrm{mg},{ }^{20}$ despite transient suppression of COX-1-dependent $\mathrm{PGI}_{2}$ release. ${ }^{18}$ It is not established that the greater suppression of $\mathrm{PGI}_{2}$ formation produced by higher doses of aspirin is sufficient to initiate or predispose to thrombosis. However, two lines of evidence suggest that $\mathrm{PGI}_{2}$ is thromboprotective. First, mice lacking the $\mathrm{PGI}_{2}$ receptor exhibit increased susceptibility to injury-induced thrombosis. ${ }^{21}$ Second, the cardiovascular toxicity associated with COX-2 inhibitors ${ }^{22}$ also supports the concept that $\mathrm{PGI}_{2}$ is important for thromboresistance in the setting of inadequate inhibition of platelet $\mathrm{TXA}_{2}$ biosynthesis. ${ }^{23}$

\subsection{Aspirin Pharmacokinetics}

Aspirin is rapidly absorbed in the stomach and upper intestine. Plasma levels peak 30 to 40 min after aspirin ingestion, and inhibition of platelet function is evident within $1 \mathrm{~h}$. In contrast, it can take 3 to $4 \mathrm{~h}$ to reach peak plasma levels after administration of enteric-coated aspirin. Therefore, if a rapid effect is required and only enteric-coated tablets are available, the tablets should be chewed instead of swallowed intact. The oral bioavailability of regular aspirin tablets is $\sim 40 \%$ to $50 \%$ over a wide range of doses. ${ }^{24}$ A considerably lower bioavailability has been reported for enteric-coated tablets and for sustained-release, microencapsulated preparations. ${ }^{24}$ The lower bioavailability of some enteric-coated preparations and their poor absorption from the higher $\mathrm{pH}$ environment of the small intestine may result in inadequate platelet inhibition when these preparations are used at low doses, particularly in heavier subjects. ${ }^{25}$ Both a controlled-release formulation ${ }^{18}$ and a transdermal patch ${ }^{26}$ with negligible systemic bioavailability have been developed in an attempt to achieve selective inhibition of platelet $\mathrm{TXA}_{2}$ production without suppressing systemic $\mathrm{PGI}_{2}$ synthesis. The former was used successfully in the Thrombosis Prevention Trial, ${ }^{27}$ but it remains unknown whether the controlled-release formulation has any advantages over plain aspirin.

The plasma concentration of aspirin decays with a half-life of 15 to $20 \mathrm{~min}$. Despite the rapid clearance 
of aspirin from the circulation, the platelet-inhibitory effects last the life span of the platelet ${ }^{28}$ because aspirin irreversibly inactivates platelet COX-1.13,14 Aspirin also acetylates megakaryocyte COX-1, thereby inhibiting thromboxane production in newly released platelets as well as those already in the circulation. ${ }^{11,29-31}$ The mean life span of human platelets is $\sim 10$ days, which means that $\sim 10 \%$ to $12 \%$ of circulating platelets are replaced every day. ${ }^{32,33}$ The recovery of thromboxane production and thromboxane-dependent platelet aggregation after prolonged aspirin treatment is stopped is faster than what would be predicted based on the rate of platelet turnover ${ }^{20}$ possibly because of the nonlinear relationship between inhibition of platelet COX-1 activity and TXA $_{2}$ biosynthesis ${ }^{34,35}$ (Fig 2) and the capacity of small amounts of thromboxane produced by nonaspirinated platelets to sustain thromboxane-dependent platelet aggregation.

\subsection{The Optimal Dose of Aspirin}

Effectiveness of Low-Dose Aspirin: Placebocontrolled randomized trials have shown that aspirin is an effective antithrombotic agent when used long term in doses ranging between 50 and $100 \mathrm{mg} / \mathrm{d}$, and there are data to suggest that it is effective in doses as low as $30 \mathrm{mg} / \mathrm{d}$.9,10 At a dose of $75 \mathrm{mg} / \mathrm{d}$, aspirin was shown to (1) reduce the risk of acute myocardial infarc- tion (MI) or death in patients with unstable angina ${ }^{36}$ or chronic stable angina, ${ }^{37}(2)$ reduce the risk of stroke or death in patients with transient cerebral ischemia, ${ }^{38}$ and (3) reduce the risk of stroke after carotid endarterectomy. ${ }^{39}$ In the European Stroke Prevention Study (ESPS)-2, aspirin $25 \mathrm{mg}$ bid reduced the risk of stroke and the composite outcome of stroke or death in patients with prior stroke or transient ischemic attack (TIA). ${ }^{40}$ In the European Collaboration on Low-dose Aspirin in Polycythemia vera trial, ${ }^{41}$ aspirin $(100 \mathrm{mg} / \mathrm{d})$ was effective in preventing thrombotic complications in patients with polycythemia vera, even in the face of higher-than-normal platelet counts. The lowest doses of aspirin demonstrated to be effective for these various indications are shown in Table 1.

Aspirin Dose Comparisons: The clinical effects of different doses of aspirin have been directly compared in randomized controlled trials. ${ }^{42-48}$ In the United Kingdom-Transient Ischaemic Attack (UK-TIA) study that randomized 2,435 patients after a TIA or minor ischemic stroke to receive one of two doses of aspirin or placebo, aspirin doses of 300 and $1,200 \mathrm{mg} / \mathrm{d}$ were associated with a similar rate of MI, major stroke, or vascular death $(20 \%$ and $20 \%$, respectively; OR, 1.03; 95\% CI, 0.83-1.29). ${ }^{42}$ In the Dutch TIA trial, which randomized 3,131 patients after a TIA or minor ischemic stroke, aspirin doses of 30 and $283 \mathrm{mg} / \mathrm{d}$
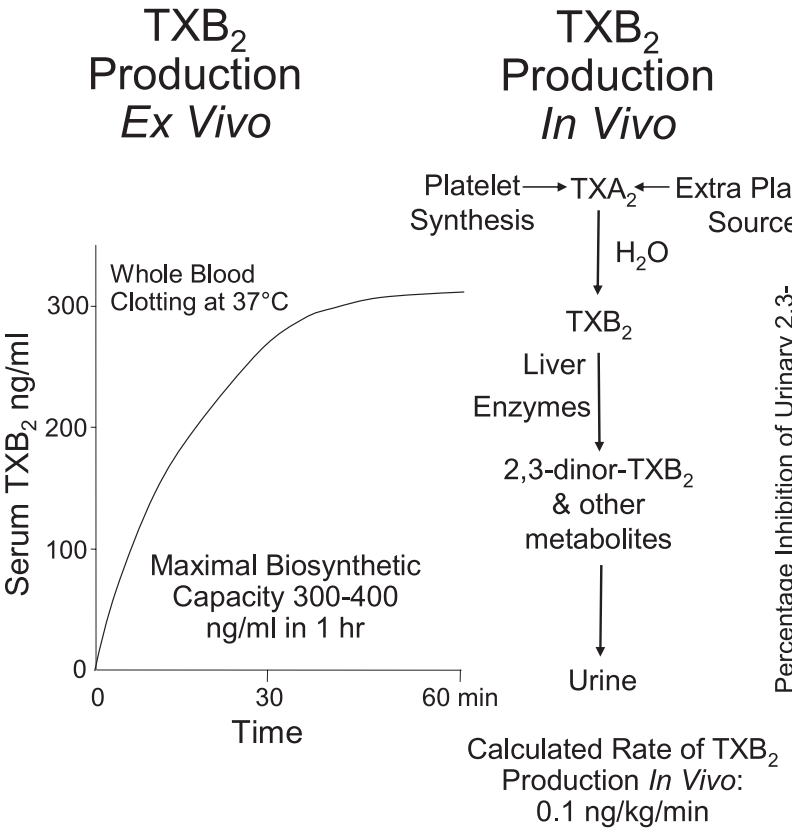

\section{Pharmacologic Inhibition Ex Vivo vs In Vivo}

FIGURE 2. Maximal capacity of human platelets to synthesize $\mathrm{TXB}_{2}$, rate of $\mathrm{TXB}_{2}$ production in healthy subjects, and relationship between the inhibition of platelet cyclooxygenase activity and $\mathrm{TXB}_{2}$ biosynthesis in vivo. Left, The level of $\mathrm{TXB}_{2}$ production stimulated by endogenous thrombin during whole-blood clotting at $37^{\circ} \mathrm{C} .{ }^{34}, 35$ Center, The metabolic fate of $\mathrm{TXA}_{2}$ in vivo and the calculated rate of its production in healthy subjects on the basis of $\mathrm{TXB}_{2}$ infusions and measurement of its major urinary metabolite. Right, The nonlinear relationship between inhibition of serum $\mathrm{TXB}_{2}$ measured ex vivo and the reduction in the excretion of thromboxane metabolite measured in vivo. ${ }^{31} \mathrm{TXA}_{2}=$ thromboxane $\mathrm{A}_{2} ; \mathrm{TXB}_{2}=$ thromboxane $\mathrm{B}_{2}$. 
Table 1-Vascular Disorders for Which Aspirin Has Been Shown to Be Effective and Lowest Effective Dose

\begin{tabular}{|c|c|}
\hline Disorder & $\begin{array}{c}\text { Lowest Effective } \\
\text { Daily Dose, mg }\end{array}$ \\
\hline Transient ischemic attack and ischemic stroke & 50 \\
\hline Men at high cardiovascular risk & 75 \\
\hline Hypertension & 75 \\
\hline Stable angina & 75 \\
\hline Unstable angina $^{\mathrm{a}}$ & 75 \\
\hline Severe carotid artery stenosis ${ }^{\mathrm{a}}$ & 75 \\
\hline Polycythemia vera & 100 \\
\hline Acute myocardial infarction ${ }^{\mathrm{a}}$ & 160 \\
\hline Acute ischemic stroke ${ }^{a}$ & 160 \\
\hline
\end{tabular}

aHigher doses have been tested in other trials and not found to confer any greater risk reduction.

were associated with a similar rate of MI, stroke, or cardiovascular death ( $14.7 \%$ and $15.2 \%$, respectively; hazard ratio [HR], 0.91; 95\% CI, 0.76-1.09).47 The ASA and Carotid Endarterectomy (ACE) trial reported that the risk of stroke, MI, or death within 3 months of carotid endarterectomy was significantly lower for patients taking aspirin 81 or $325 \mathrm{mg} / \mathrm{d}$ than for those taking 650 or $1,300 \mathrm{mg} / \mathrm{d}(6.2 \%$ vs $8.4 \%, P=.03) .{ }^{46}$ The Clopidogrel Optimal Loading Dose Usage to Reduce Recurrent Events/Organization to Assess Strategies for Ischemic Syndromes (CURRRENTOASIS 7) trial, which included 25,086 patients with acute coronary syndromes (ACSs), found that 30 days of treatment with aspirin 300 to $325 \mathrm{mg} / \mathrm{d}$ was no more effective than aspirin 75 to $100 \mathrm{mg} / \mathrm{d}$ for the prevention of stroke, MI, or cardiovascular death (4.2\% and $4.4 \%$, respectively; HR, $0.97 ; 95 \%$ CI, 0.86-1.09). ${ }^{48}$ Thus, on the basis of results from randomized studies comparing different doses of aspirin, there is no convincing evidence that higher doses are any more effective at reducing the risk of serious vascular events than lower doses. In fact, the indirect comparisons reported in the overview of the Antithrombotic Trialists' Collaboration (Table 2) and the results of several direct randomized comparisons are compatible with the reverse; that is, there is blunting of the antithrombotic effect with higher doses of aspirin, a finding consistent with dose-dependent inhibition of $\mathrm{PGI}_{2}$.

The Range of Effective Aspirin Doses: The antithrombotic effects of a range of doses of aspirin have

Table 2-Indirect Comparison of Aspirin Doses Reducing Vascular Events in High-Risk Patients

\begin{tabular}{lccc}
\hline \hline Aspirin Dose, mg/d & No. Trials & No. Patients & Odds Reduction, \% \\
\hline $500-1,500$ & 34 & 22,451 & $19 \pm 3$ \\
\hline $160-325$ & 19 & 26,513 & $26 \pm 3$ \\
\hline $75-150$ & 12 & 6,776 & $32 \pm 6$ \\
\hline$<75$ & 3 & 3,655 & $13 \pm 8$ \\
\hline
\end{tabular}

been compared with an untreated control group in a number of thrombotic vascular disorders. The aspirin doses have ranged from 50 to $1,500 \mathrm{mg} / \mathrm{d}$. Aspirin has been shown to be effective in the following conditions: unstable angina where the incidence of acute MI or death was significantly reduced in four separate studies using daily doses of $75,{ }^{36} 325,{ }^{49} 650,50$ or 1,300 $\mathrm{mg}^{51}$; stable angina where a dose of $75 \mathrm{mg} / \mathrm{d}$ reduced the incidence of acute MI or sudden death ${ }^{37}$; aortocoronary bypass surgery where the incidence of early graft occlusion was similarly reduced with daily doses of $100,{ }^{52} 325,{ }^{53} 975,54$ or 1,200 mg54; thromboprophylaxis in patients with prosthetic heart valves who also received warfarin where the incidence of systemic embolism was reduced with daily doses of $100,{ }^{55} 500,{ }^{56}$ or $1,500 \mathrm{mg}^{57,58}$; thromboprophylaxis in long-term hemodialysis patients with arterial venous shunts where a dose of $160 \mathrm{mg} / \mathrm{d}$ was shown to be effective $^{59}$; acute MI in which a dose of $162.5 \mathrm{mg} / \mathrm{d}$ reduced 35-day mortality as well as nonfatal reinfarction and stroke ${ }^{60}$; transient cerebral ischemia in which doses between 50 and 1,200 $\mathrm{mg} / \mathrm{d}$ were effective $^{38,40,42,61-63}$; acute ischemic stroke where doses of 160 to $300 \mathrm{mg} / \mathrm{d}$ were effective in reducing early mortality and stroke recurrence ${ }^{64,65}$; and polycythemia vera in which $100 \mathrm{mg} / \mathrm{d},{ }^{41}$ but not $900 \mathrm{mg} / \mathrm{d},{ }^{66}$ was effective in reducing fatal and nonfatal vascular events. Thus, aspirin is an effective antithrombotic agent at doses between 50 and $1,500 \mathrm{mg} / \mathrm{d}$. Based on the results of the Dutch TIA study, it is also possible that $30 \mathrm{mg} / \mathrm{d}$ is effective. ${ }^{47}$

Effect of Aspirin Dose on GI Side Effects and Bleeding: There is evidence that the GI side effects of aspirin are dose dependent. Thus, aspirin doses of $\sim 300 \mathrm{mg} / \mathrm{d}$ are associated with fewer GI side effects than doses of $\sim 1,200 \mathrm{mg} / \mathrm{d} .{ }^{42}$ There is also evidence that aspirin doses $\leq 100 \mathrm{mg} / \mathrm{d}$ are associated with fewer side effects than $300 \mathrm{mg} / \mathrm{d} .{ }^{47} \mathrm{In}$ an observational analysis in patients with ACS, the Clopidogrel in Unstable Angina to Prevent Recurrent Events (CURE) investigators demonstrated that aspirin $\leq 100 \mathrm{mg} / \mathrm{d}$ alone or in combination with clopidogrel was associated with lower rates of major or life-threatening bleeding complications than aspirin alone at a dose of $\geq 200 \mathrm{mg} / \mathrm{d} .{ }^{67} \mathrm{In}$ the randomized CURRENT-OASIS 7 trial, aspirin given at a dose of 75 to $100 \mathrm{mg} / \mathrm{d}$ produced less GI bleeding than a dose of 300 to $325 \mathrm{mg} / \mathrm{d}$. The incidence of other types of major bleeding was not different between the two groups. ${ }^{48}$ In summary, the lack of a doseresponse relationship for the efficacy of aspirin in clinical studies and the dose dependence of GI bleeding support the use of lowest proven effective doses of aspirin as the most appropriate strategy to maximize efficacy and minimize toxicity (Table 1). ${ }^{9}$ 


\subsection{High On-Treatment Platelet \\ Reactivity (Aspirin Resistance)}

High platelet reactivity in patients prescribed aspirin has been associated with an increased risk of thrombotic events. Therefore, this phenomenon has been used as one definition of aspirin resistance. Observational studies demonstrate that about one-third of patients treated with aspirin demonstrate less-thanexpected inhibition of agonist-induced platelet aggregation and increased levels of urinary thromboxane. . $^{8-10}$ Estimates of the prevalence of high on-treatment platelet reactivity are affected by differences among the studies in patient characteristics (eg, age, female sex, diabetes), concomitant therapies (particularly NSAIDs, eg, ibuprofen), the laboratory test used to measure the antiplatelet effects of aspirin (light transmission or whole-blood aggregometry, shear stressinduced platelet activation, expression of activation markers on the platelet surface as measured by flow cytometry, inhibition of thromboxane production), the cutoff used to define high on-treatment reactivity, and patient compliance with aspirin therapy. ${ }^{25}$ Despite these differences, high platelet reactivity in patients prescribed aspirin has been consistently associated with a twofold to fourfold higher risk of MI, stroke, or death. $9,10,26,27$

If thrombotic events in aspirin-treated patients with high on-treatment platelet reactivity were solely attributable to reduced responsiveness to aspirin, strategies aimed at improving the response would be expected to reduce this risk. Observational studies suggest that aspirin inhibits platelet function ${ }^{68-72}$ and coagulation ${ }^{73-79}$ in a dose-dependent manner; a finding confirmed in a randomized dose comparison. ${ }^{80}$ Thus, in a randomized, double-blind, crossover trial that included 125 patients with stable coronary artery disease, Gurbel and colleagues ${ }^{80}$ demonstrated that at doses of 81,162 , or $325 \mathrm{mg} / \mathrm{d}$, aspirin inhibited adenosine diphosphate (ADP) and collagen-induced platelet aggregation, blocked sheardependent platelet aggregation measured by the PFA-100 device, and reduced urinary thromboxane concentrations in a dose-dependent manner. Most of the patients included in this study demonstrated near-complete inhibition of arachidonic acid-induced platelet aggregation with the $81-\mathrm{mg} / \mathrm{d}$ dose of aspirin, but higher aspirin doses reduced the proportion of patients in whom arachidonic acid-induced aggregation exceeded a cutoff value of $20 \%{ }^{80}$ However, the dose-dependent inhibition of platelet function and thromboxane production by aspirin observed in this study does not fit with the results of the CURRENT-OASIS 7 trial, which failed to demonstrate a reduction in the risk of thrombotic events with higher doses of aspirin (See section 1.3 "The
Optimal Dose of Aspirin"). How do we explain this apparent paradox?

The most likely explanation is that the relationship between platelet reactivity and thrombotic risk is confounded by comorbidities, such as smoking or diabetes, that affect both platelet function and cardiovascular risk. It is also possible that the laboratory tests used to measure platelet reactivity fail to monitor the mechanism by which aspirin reduces the risk of thrombotic events. Many of these tests use nonphysiologic stimuli to induce platelet aggregation, and none assess platelet interaction with the vessel wall or the effect of aspirin on COX-2-dependent $\mathrm{PGI}_{2}$ production. Thromboxane production appears to be the most specific measure of the inhibitory effects of aspirin because thromboxane is the major biochemical end product of the platelet COX-1 biosynthetic pathway that is targeted by aspirin. However, serum thromboxane levels reflect the maximum capacity of platelets to produce thromboxane; urinary thromboxane is also produced from nonplatelet sources, and measures of thromboxane concentration do not capture the effect of aspirin on $\mathrm{PGI}_{2}$ production.

Given the multifactorial triggers of atherothrombosis and the likelihood that platelet activation and subsequent aggregation are not the sole mediators of vascular events, it is not surprising that only a fraction (usually one-fourth to one-third) of all vascular complications can be prevented by aspirin alone. There is no evidence that patients who experience a thrombotic event despite aspirin therapy benefit from treatment with higher-dose aspirin. Concomitant administration of nonselective NSAIDs, such as ibuprofen, should be avoided because, as outlined previously, these drugs can interfere with the antiplatelet effect of aspirin. ${ }^{16}$ A pharmacodynamic interaction between naproxen and aspirin has also been described, ${ }^{81}$ but this does not appear to occur with rofecoxib, ${ }^{82}$ celecoxib, ${ }^{83}$ or diclofenac, ${ }^{82}$ drugs endowed with variable COX-2 selectivity. ${ }^{84}$ The US Food and Drug Administration (FDA) has issued a statement informing patients and health-care professionals that ibuprofen can interfere with the antiplatelet effect of low-dose aspirin $(81 \mathrm{mg} / \mathrm{d})$, potentially rendering aspirin less effective when used for cardioprotection or stroke prevention..$^{85}$

\subsection{Efficacy and Safety}

(a) Prevention of Atherothrombosis: The efficacy and safety of aspirin are documented from analyses of $>100$ randomized controlled trials that have included thousands of patients representing the entire spectrum of atherosclerosis, ranging from apparently healthy low-risk individuals to patients presenting with an acute MI or acute ischemic stroke. Trials have 
evaluated aspirin therapy of only a few weeks duration or as long as 10 years..$^{9,10}$ Although aspirin has consistently been shown to be effective in preventing fatal and nonfatal vascular events in these trials, the absolute benefits depend on the clinical setting.

In Second International Study of Infarct Survival (ISIS-2), ${ }^{59}$ a single 162.5-mg tablet of aspirin started within $24 \mathrm{~h}$ of the onset of symptoms of a suspected MI and continued at the same dose daily for 5 weeks produced highly significant reductions in vascular mortality, nonfatal reinfarction, and nonfatal stroke $(23 \%, 49 \%$, and $46 \%$, respectively). There was no associated increase in hemorrhagic stroke or GI bleeding with aspirin, although there was a small increase in minor bleeding. ${ }^{59}$ Based on the results of this study, a 5-week course of aspirin treatment in 1,000 patients with suspected acute MI will prevent $\sim 40$ vascular events, ${ }^{10}$ a proportional odds reduction of $30 \%$.

Two separate trials with a similar protocol tested the efficacy and safety of early aspirin use in acute ischemic stroke. The Chinese Acute Stroke Trial ${ }^{64}$ and the International Stroke Trial ${ }^{65}$ collectively randomized $\sim 40,000$ patients within 48 h of the onset of stroke symptoms to 2 to 4 weeks of daily aspirin therapy (at doses of 160 and $300 \mathrm{mg} / \mathrm{d}$, respectively) or to placebo. An overview analysis of the results of both trials indicated an absolute benefit of nine fewer deaths or nonfatal strokes per 1,000 patients in the first month of aspirin therapy. ${ }^{10}$ The proportional odds reduction in the risk of fatal or nonfatal vascular events was only $10 \%$ in this setting. Although the background risk of hemorrhagic stroke was threefold higher in the Chinese Acute Stroke Trial than in the International Stroke Trial, the absolute increase in this risk was similar in the two studies (an excess of 2/1,000 aspirin-treated patients). ${ }^{64,65}$

Long-term aspirin therapy confers a conclusive net benefit on the risk of subsequent MI, stroke, or vascular death among subjects with a high risk of vascular complications. These include patients with chronic stable angina, ${ }^{37}$ prior $\mathrm{MI},{ }^{10}$ unstable angina, ${ }^{36,49-51}$ history of TIA or minor stroke, ${ }^{37,40,42,62,63,86}$ and other high-risk categories. ${ }^{10}$ The proportional reduction in vascular events with long-term aspirin therapy in these various clinical settings ranges from $20 \%$ to $25 \%$ based on an overview of all of the randomized trials. ${ }^{10}$ Estimates of relative benefits based on the results of individual trials vary from no statistically significant benefit in patients with peripheral arterial disease to an $\sim 50 \%$ risk reduction in patients with unstable angina. ${ }^{10}$ In terms of absolute benefit, the protective effects of aspirin translate into avoidance of a major vascular event in 50 of 1,000 patients with unstable angina treated with aspirin for 6 months to 36 of 1,000 patients with prior MI, stroke, or TIA treated with aspirin for $\sim 30$ months. ${ }^{10}$
For patients with various manifestations of ischemic cardiac or neurologic disease, there is consensus that the optimal dose of aspirin for prevention of MI, stroke, or vascular death lies within the narrow range of 75 to $160 \mathrm{mg} / \mathrm{d}$. This concept is supported by an overview of all antiplatelet trials that showed no obvious aspirin dose dependence for the protective effects of aspirin based on direct and indirect comparisons ${ }^{10}$ as well as by the results of individual trials that randomized patients to treatment with low-dose aspirin or placebo or to two different doses of aspirin (Table 3). As discussed earlier, there is no convincing evidence that the dose requirement for the antithrombotic effect of aspirin varies in different clinical settings.

(b) Primary Prevention: Among most high-risk patient groups, the expected number of individuals avoiding a serious vascular event by using aspirin substantially exceeds the number experiencing a major bleed. It is less certain, however, whether aspirin is of benefit in apparently healthy people who are at intermediate risk for serious vascular events because they have well-established cardiovascular risk factors. The Antithrombotic Trialists' Collaboration addressed this issue in an individual participant data meta-analysis of the results of large randomized trials of aspirin for primary prevention of vascular events. ${ }^{87}$ The analysis was based on the results of six primary prevention trials that included 95,456 subjects ${ }^{27,88-92}$ with a mean follow-up of 6.9 years and a median follow-up among survivors of 5.5 years, reflecting the fact that the Women's Health Study, ${ }^{91}$ which accounted for almost one-half of the participants, had a mean follow-up of $\sim 10$ years (Table 4 ). The effects of aspirin for primary prevention were compared with its effects in high-risk settings using the results of six trials among patients with a history of MI, nine trials among patients with a history of TIA or stroke, and one trial in patients with moderately severe diabetic retinopathy. ${ }^{10}$

The results of the Antithrombotic Trialists' Collaboration individual patient meta-analysis indicated a $12 \%$ proportional reduction in the incidence of serious vascular events (rate ratio [RR], 0.88; $95 \%$ CI, $0.82-0.94 ; P=.0001$ ) and an $18 \%$ proportional reduction in the incidence of major coronary events (RR, 0.82; 95\% CI, 0.75-0.90; $P<.0001)$. Most of the benefit of aspirin was due to a $23 \%$ reduction in nonfatal MI (RR, 0.77; 95\% CI, 0.67-0.89; $P<.0001$ ); there was no apparent reduction in cardiovascular death (RR, 0.95; 95\% CI, 0.78-1.15; $P=.50)$. Aspirin was associated with a nonsignificant $10 \%$ reduction in nonhemorrhagic stroke (RR, 0.90; 95\% CI, 0.80-1.01; $P=.08)$.

Aspirin had no significant effect on the aggregate of all vascular causes of death (RR, 0.98; 95\% CI, 
Table 3-[Section 2.4] Dose and Time Dependence of the Effects of Aspirin on Platelets and Inflammatory Cells

\begin{tabular}{|c|c|c|c|c|c|}
\hline Cellular Target & Enzyme & Single Dose, mga & $\begin{array}{l}\text { Duration of Prostanoid } \\
\text { Suppression, h }\end{array}$ & $\begin{array}{c}\text { Cumulative Effects Upon } \\
\text { Repeated Dosing }\end{array}$ & Daily Dose, $\mathrm{mg}^{\mathrm{b}}$ \\
\hline Platelets & COX-1 & 100 & $24-48$ & Yes & $50-81$ \\
\hline Inflammatory cells & COX-2 & $\geq 650$ & $3-4$ & No & $3,000-5,000$ \\
\hline
\end{tabular}

0.87-1.10; $P$ not significant), and there was no evidence of a protective effect on the two-thirds of vascular deaths due to coronary heart disease (RR, 0.95; $95 \%$ CI, $0.78-1.15 ; P=.5)$, the one-sixth due to stroke (RR, $1.21 ; 95 \% \mathrm{CI}, 0.84-1.74 ; P=.2$ ), or the remaining vascular causes of death $(\mathrm{RR}, 0.90 ; 95 \% \mathrm{CI}$, $0.65-1.26 ; P=.4)$. Aspirin had no significant effect on nonvascular mortality (RR, 0.93; 95\% CI, 0.85-1.02; $P=.1$ ) or unknown causes of death (RR, 0.95; 95\% CI, 0.75-1.21; $P$ not significant) but increased the risk of major extracranial bleeds (RR, 1.55; 95\% CI, $1.31-1.83 ; P<.0001$ ).

The absolute benefits of aspirin were summarized under the term "occlusive vascular events," that is, vascular events other than hemorrhagic stroke or fatal extracranial bleeds. Among low-risk individuals (annual risk of coronary heart disease $\leq 1 \%$ ), allocation to aspirin resulted in the avoidance of four (95\% CI, 2-6) occlusive vascular events per 1,000 after 5 years, which was chiefly attributable to three (95\% CI, 1-5) fewer major coronary events. This benefit was offset by two (95\% CI, 1-3) additional major extracranial bleeds per 1,000 over the same 5 -year period, but there was no significant excess risk of hemorrhagic stroke $(0.1$ [ $95 \% \mathrm{CI},-0.5$ to 0.7 ] excess; $P$ not significant). Among the much smaller number of moderate-risk participants (yearly coronary heart disease risk $>1 \%$ ), the net effect of aspirin over 5 years on occlusive vascular events was statistically uncertain (13 [95\% CI, -3-29] fewer; $P=.1$ ) because despite a definite reduction in major coronary events (18 [95\% CI, 5-30] fewer per 1,000), there was no significant reduction in presumed ischemic stroke (one fewer per 1,000 [95\% CI, nine more to 11 fewer]), and there was an excess of both hemorrhagic stroke (five [95\% CI, 1-9] more per 1,000) and major bleeds (4 more per 1,000 [95\% CI, one fewer to 10 more]). About one-half of the hemorrhagic strokes were fatal (and the remainder would be expected to result in moderate or severe disability), so this hazard substantially offsets any cardiac benefits in moderate-risk individuals.

The results of three subsequently completed primary prevention trials involving 7,165 patients with diabetes, peripheral arterial disease, or both (Table $4^{27,88-95}$ ) are consistent with those of the indi- vidual patient meta-analysis performed by the Antithrombotic Trialists' Collaboration. ${ }^{93-95}$ A meta-analysis of all nine primary prevention trials demonstrated a borderline significant reduction in all-cause mortality with aspirin but no reduction in cardiovascular mortality ${ }^{96}$ a finding that raises the possibility that aspirin also prevents nonvascular (cancer) mortality (Discussed in "Cancer Incidence and Mortality").

Previous meta-analyses of the effects of antiplatelet therapy in persons at high risk of occlusive vascular disease ${ }^{7}$ have shown that the benefits of aspirin far exceed the bleeding risks. By contrast, the majority $(92 \%)$ of participants in the primary prevention trials was at low absolute risk of coronary disease; on average, the annual risk of a vascular event in the primary prevention trials was only about one-tenth of that in the high-risk trials. Although the proportional benefits of aspirin appeared broadly similar when used for primary or secondary prevention, the absolute benefits of aspirin in the primary prevention trials were very small. When used for primary prevention, fewer than one person of every 1,000 treated with aspirin would avoid an occlusive vascular event, whereas a comparably small number would experience a major extracranial bleed. Until the benefits of aspirin can be defined more precisely, therefore, the possibility of a benefit for vascular prevention does not seem to justify the potential for harms. However, these estimates do not take into account the benefits of aspirin for the prevention of cancer and cancerrelated mortality, which might tip the balance in favor of aspirin use for primary prevention. Additional trials evaluating the utility of aspirin for primary prevention of cardiovascular disease in elderly patients ${ }^{97,98}$ and in patients with diabetes ${ }^{99}$ are ongoing. Readers are referred to the prevention of cardiovascular disease article in this supplement by Vandvik et al. ${ }^{100}$

(c) Atrial Fibrillation: Anticoagulant therapy with dose-adjusted warfarin (international normalized ratio, 2.0-3.0), ${ }^{101}$ the direct thrombin inhibitor dabigatran etexilate, ${ }^{102}$ or the direct factor Xa inhibitors rivaroxaban and apixaban ${ }^{103}$ is very effective in reducing the risk of stroke in patients with nonvalvular atrial fibrillation. The efficacy of aspirin (in doses ranging from $75-1,200 \mathrm{mg} / \mathrm{d}$ ) has been compared with that of 


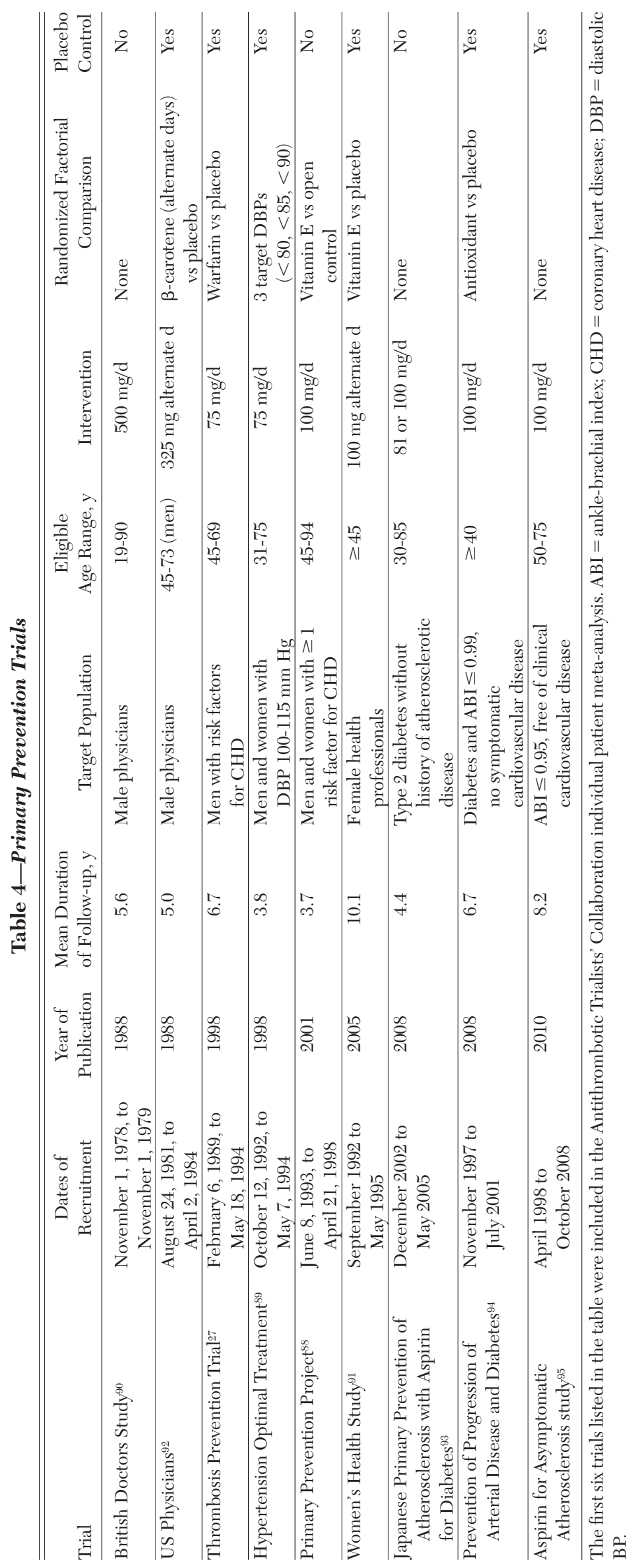


placebo or no antiplatelet treatment in seven randomized trials that included 3,990 patients with nonvalvular atrial fibrillation. ${ }^{101}$ A pooled analysis revealed a relative risk reduction of $\sim 19 \%$ with aspirin compared with placebo or no treatment $(95 \% \mathrm{CI}$, $-1 \%-35 \%$ ), which is consistent with the $22 \%$ (95\% CI, 6\%-35\%) relative risk reduction obtained when comparing any antiplatelet therapy with placebo or no antiplatelet therapy for stroke prevention in patients with nonvalvular atrial fibrillation. ${ }^{101}$ Pooled analysis of 10 trials involving 4,620 patients with nonvalvular atrial fibrillation revealed that dose-adjusted vitamin $\mathrm{K}$ antagonist therapy was significantly more effective than aspirin, with a $39 \%$ relative risk reduction (95\% CI, 19\%-53\%). ${ }^{104}$ Warfarin is also more effective than the combination of aspirin and clopidogrel. ${ }^{105}$

The efficacy of antiplatelet therapy for stroke prevention in atrial fibrillation has been confirmed by the results of the Atrial Fibrillation Clopidogrel Trial with Irbesartan for Prevention of Vascular Events (ACTIVE) A trial, which compared the combination of aspirin plus clopidogrel with aspirin alone in 7,554 patients deemed ineligible for warfarin. ${ }^{106}$ Aspirin plus clopidogrel reduced the risk of major vascular events, comprising the composite of stroke, MI, non-CNS embolism, or death from vascular causes, by $11 \%$ compared with aspirin (95\% CI, $2 \%-19 \%)$ primarily because of a $28 \%$ reduction in stroke (95\% CI, 17\%-38\%). However, the combination of clopidogrel plus aspirin is less effective than warfarin and is associated with a similar risk of bleeding. ${ }^{105}$ Readers are referred to You et al ${ }^{107}$ in this guideline for further discussion of the use of antiplatelet therapy for stroke prevention in patients with atrial fibrillation.

(d) VTE: The Pulmonary Embolism Prevention (PEP) trial results demonstrated that aspirin is effective in preventing VTE after major orthopedic surgery. ${ }^{108}$ This double-blind, multicenter study included 13,356 patients undergoing surgery for hip fracture and an additional 4,088 patients undergoing elective hip or knee arthroplasty. Patients were randomized to receive aspirin $(160 \mathrm{mg} / \mathrm{d})$ or placebo for 5 weeks, with the first dose administered prior to surgery. Other forms of prophylaxis were allowed, and either heparin or low-molecular-weight heparin was used in $\sim 40 \%$ of the patients. Among the 13,356 patients undergoing surgery for hip fracture, aspirin produced a 36\% reduction in symptomatic DVT or pulmonary embolism (absolute risk reduction, $0.9 \% ; P=.0003$ ). A similar relative risk reduction was observed in aspirin-treated patients who did or did not receive concomitant heparin or low-molecular-weight heparin. These results are consistent with those of meta-analyses performed by the Antiplatelet Trialists' Collaboration ${ }^{109}$ and by Sandercock and colleagues ${ }^{110}$ of antiplatelet trials in patients with stroke.

When compared with warfarin, heparin, lowmolecular-weight heparin, or danaparoid, aspirin was associated with similar or higher rates of DVT detected by screening ultrasound or venography; however, the frequency of symptomatic events was low. ${ }^{111}$ A large randomized controlled trial is required to compare the effectiveness of aspirin with that of anticoagulants for the prevention of fatal or symptomatic VTE events. Readers are referred to Falck-Ytter et al ${ }^{112}$ in this guideline for further discussion of the use of antiplatelet therapy for prevention of VTE.

(e) Placental Insufficiency: Preeclampsia and fetal growth restriction are believed to be related to reduced placental blood flow, which is believed to be caused by constriction, thrombosis, or both of small placental arteries. ${ }^{113}$ The initial reports that low-dose aspirin therapy reduces the risk of severe low birth weight among newborns ${ }^{114}$ and lowers the need for cesarean section in mothers with pregnancy-induced hypertension ${ }^{114}$ led to the widespread use of prophylactic aspirin for prevention of preeclampsia. Subsequently, several larger trials reported no beneficial effects of aspirin. ${ }^{115-121}$ However, a systematic review of data from 59 trials in 37,560 women confirmed that antiplatelet therapy (mostly aspirin $60 \mathrm{mg} / \mathrm{d}$ ) is beneficial. Aspirin was associated with a $17 \%$ decrease in the risk of preeclampsia, an $8 \%$ reduction in the risk of preterm birth, a $14 \%$ reduction in the risk of fetal or neonatal death, and a $10 \%$ reduction in smallfor-gestational age babies. ${ }^{122}$ An individual patient meta-analysis of 31 trials involving 32,217 patients who received antiplatelet therapy for primary prevention of preeclampsia revealed a consistent benefit of aspirin for the prevention of eclampsia (overall $10 \%$ relative risk reduction) in all of the subgroups studied (first pregnancy with or without any high risk factor; second pregnancy with or without high risk factors or history of hypertensive disorder of pregnancy; preexisting renal disease, diabetes, hypertension, or previous infant small for gestational age; maternal age; singleton or multiple pregnancy; and timing of starting of treatment or intended aspirin dose $\leq 75 \mathrm{mg} / \mathrm{d}$ or $\geq 75 \mathrm{mg} / \mathrm{d}$ ). ${ }^{123}$ Aspirin given in doses ranging from 50 to $150 \mathrm{mg} / \mathrm{d}$ accounted for $98 \%$ of women included in this data set. Readers are referred to Bates et al ${ }^{124}$ in this guideline for further discussion of the use of antithrombotic therapy during pregnancy.

(f) Cancer Incidence and Mortality: There is compelling evidence from randomized controlled trials that aspirin reduces the incidence of colorectal cancer 
and cancer mortality. ${ }^{125,126}$ An individual patient metaanalysis of eight randomized controlled trials that included 25,570 subjects demonstrated that compared with no aspirin, daily aspirin for a scheduled mean treatment duration of at least 4 years reduced the odds of cancer deaths by $21 \%$ ( $95 \%$ CI, $8 \%-32 \%$ ). The mortality benefit appeared to be unrelated to aspirin dose, only became apparent after 5 years of follow-up, and the absolute benefit increased over time. The greatest mortality benefit was seen with adenocarcinoma. Among patients aged $\geq 65$ years at the start of the trials, the absolute reduction in cancer deaths over 20 years was $7.1 \%$ (95\% CI, 2.4\%-11.7\%). ${ }^{126}$ Separate analyses based on individual patient data from four trials of 14,033 patients followed for a median of 18.3 years demonstrated that aspirin (at doses of 75-300 mg/d) also reduced the incidence of colorectal cancer. Furthermore, an analysis from the Dutch TIA trial suggested that the risk of fatal colorectal cancer was higher with aspirin doses of $30 \mathrm{mg} / \mathrm{d}$ than it was with a dose of $283 \mathrm{mg} / \mathrm{d}$. ${ }^{126}$

(g) Adverse Effects of Aspirin: Aspirin-induced impairment of primary hemostasis cannot be separated from its antithrombotic effect and appears to be similar with all doses $\geq 75 \mathrm{mg} / \mathrm{d} .{ }^{9}$ The balance between preventing thrombotic events and causing bleeding with aspirin critically depends on the absolute thrombotic vs hemorrhagic risk of the patient. Thus, in individuals at low risk for vascular occlusion (eg, $\leq 1 \%$ per year), the very small reduction of vascular events is probably offset by bleeding complications. In contrast, in patients at high risk of cardiovascular or cerebrovascular complications (eg, $>3 \%$ per year), the substantial absolute benefit of aspirin prophylaxis clearly outweighs the harm (Table 5). For example, the absolute excess of major bleeds (ie, those requiring transfusion) in patients with acute MI is $\sim 1 / 100$ th the absolute number of major vascular events avoided by aspirin therapy..$^{10}$

The overall risk of major extracranial and intracranial hemorrhage associated with antiplatelet drugs is difficult to assess in individual trials because their incidence is $<1 \%$ per year. This makes detection of even a $50 \%$ to $60 \%$ relative increase in risk unrealistic in most trials of a few thousand patients.

Aspirin-induced GI toxicity, as detected in randomized clinical trials, appears to be dose-related, with doses in the range of 30 to $1,300 \mathrm{mg} / \mathrm{d}$. ${ }^{127}$ This conclusion is based on both indirect comparisons of different trials and direct randomized comparisons of different aspirin doses, as reviewed previously in this article. The dose-response relationship for GI toxicity is believed to reflect at least two COX-1-dependent components: dose-dependent inhibition of COX-1 in the GI mucosa and dose-independent (within the range of examined
Table 5-Benefit and Harm of Antiplatelet Prophylaxis With Aspirin in Different Settings

\begin{tabular}{|c|c|c|}
\hline Clinical Setting & $\begin{array}{c}\text { Benefits, No. } \\
\text { of Patients in Whom } \\
\text { a Major Vascular } \\
\text { Event Is Avoided per } \\
1,000 / \mathrm{y}^{\mathrm{a}}\end{array}$ & $\begin{array}{c}\text { Harm, No. } \\
\text { of Patients in Whom } \\
\text { a Major GI Bleeding } \\
\text { Event Is Caused per } \\
1,000 / \mathrm{y}^{\mathrm{b}}\end{array}$ \\
\hline $\begin{array}{l}\text { Patients at low to high } \\
\text { cardiovascular risk }\end{array}$ & $1-2$ & $1-2$ \\
\hline Essential hypertension & $1-2$ & $1-2$ \\
\hline Chronic stable angina & 10 & $1-2$ \\
\hline $\begin{array}{l}\text { Prior myocardial } \\
\text { infarction }\end{array}$ & 20 & $1-2$ \\
\hline Unstable angina & 50 & $1-2$ \\
\hline \multicolumn{3}{|c|}{$\begin{array}{l}\text { aBenefits are calculated from randomized trial data reviewed in this } \\
\text { article and depicted in Figure } 3 \text {. } \\
\text { bExcess of upper-GI bleedings are estimated from a background rate } \\
\text { of one event per } 1,000 / y \text { in the general population of nonusers and a } \\
\text { relative risk of } 2.0 \text { to } 3.0 \text { associated with aspirin prophylaxis. Such } \\
\text { an estimate assumes comparability of other risk factors for upper- } \\
\text { GI bleeding, such as age and concomitant use of nonsteroidal } \\
\text { antiinflammatory drugs and may actually underestimate the absolute } \\
\text { risk in an elderly population exposed to primary prevention. }\end{array}$} \\
\hline
\end{tabular}

doses) inhibition of COX-1 in platelets. ${ }^{6}$ Thus, it is not surprising that the antithrombotic effect of aspirin can be dissociated, at least in part, from GI bleeding. Even at low doses, aspirin causes serious GI bleeding. ${ }^{40,47}$ Because of the underlying prevalence of gastric mucosal erosions related to concurrent use of other NSAIDs and Helicobacter pylori infection in the general population, it should be expected that any dose of aspirin will cause more GI bleeding from preexisting lesions than placebo. Consistent with this mechanistic interpretation, the relative risk of hospitalization due to upper-GI bleeding and perforation associated with low-dose aspirin therapy (mostly $100-300 \mathrm{mg} / \mathrm{d}$ ) is comparable to that with other antiplatelet drugs and anticoagulants (ie, 2.3 [95\% CI, 1.7-3.2], 2.0 [95\% CI, 1.4-2.7], and 2.2 [95\% CI, 1.4-3.4], respectively, in a large population-based observational study $\left.{ }^{128}\right)$.

In the 2002 overview of randomized trials of aspirin for secondary vascular prevention performed by the Antithrombotic Trialists' Collaboration, ${ }^{10}$ information was available on 787 major extracranial hemorrhages in 60 trials recording at least one such hemorrhage. These were generally defined as hemorrhages that were fatal or required transfusion; among them, 159 (20\%) caused death. Overall, the proportional increase in risk of a major extracranial bleed with antiplatelet therapy was about one-half (OR, 1.6; 95\% CI, 1.4-1.8), with no significant difference between the proportional increases observed in each of the five high-risk categories of patients. A similar proportional increase in extracranial bleeding was obtained in the 2009 individual patient metaanalysis by the Antithrombotic Trialists' Collaboration of six trials of aspirin for primary prevention that 


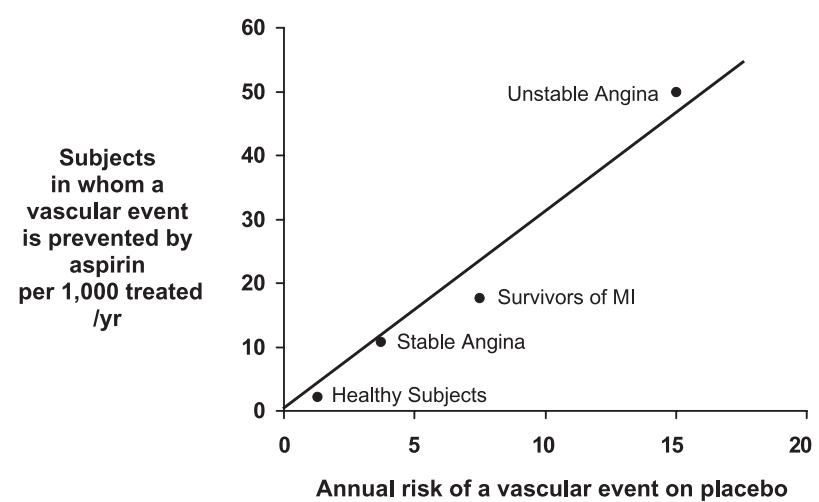

FIGURE 3. The absolute risk of vascular complications is the major determinant of the absolute benefit of antiplatelet prophylaxis. Data are plotted from placebo-controlled aspirin trials in different clinical settings. For each category of patients, the abscissa denotes the absolute risk of experiencing a major vascular event as recorded in the placebo arm of the trials. The absolute benefit of antiplatelet treatment is reported on the ordinate as the number of subjects in whom an important vascular event (nonfatal MI, nonfatal stroke, or vascular death) is actually prevented by treating 1,000 subjects with aspirin for 1 year. MI = myocardial infarction.

included 554 extracranial hemorrhages (OR, 1.5; $95 \%$ CI, 1.3-1.8). ${ }^{87}$

A case-control study with hospital and community controls examined the risks of hospitalization for bleeding peptic ulcer associated with three different regimens of aspirin prophylaxis. ${ }^{129}$ ORs were calculated for different doses of aspirin: $75 \mathrm{mg}$ (2.3; 95\% CI, 1.2-4.4), $150 \mathrm{mg}(3.2 ; 95 \% \mathrm{CI}, 1.7-6.5)$, and $300 \mathrm{mg}$ (3.9; 95\% CI, 2.5-6.3). Additional epidemiologic studies have found a dose-response relationship between aspirin prescription and upper-GI complications, as reviewed by García Rodríguez et al. ${ }^{130}$ It has been calculated that $\sim 900$ of the 10,000 episodes of ulcer bleeding occurring in persons aged $>60$ years each year in England and Wales could be associated with and ascribed to prophylactic aspirin use. ${ }^{129}$ If the assumptions from indirect comparisons are correct, a general change to lower doses $(75 \mathrm{mg} / \mathrm{d})$ of aspirin would not eliminate the risk but would reduce it by $\sim 40 \%$ compared with a $300-\mathrm{mg}$ dose and by $30 \%$ compared with a 150 -mg dose. ${ }^{129}$ The mortality rate among patients who are hospitalized for NSAID-induced upper-GI bleeding is $5 \%$ to $10 \%$. $^{131,132}$

The widely held belief that enteric-coated and buffered aspirin preparations are less likely to cause major upper-GI bleeding than plain tablets was evaluated in a multicenter case-control study. ${ }^{133}$ The relative risks of upper-GI bleeding for plain, entericcoated, and buffered aspirin at average daily doses of $\leq 325 \mathrm{mg}$ were $2.6,2.7$, and 3.1 , respectively. At doses $>325 \mathrm{mg}$, the relative risk was 5.8 for plain and 7.0 for buffered aspirin; there were insufficient data to evaluate enteric-coated aspirin at this dose level. ${ }^{133}$
Similar conclusions were reached by a case-control study using data from the UK General Practice Research Database. ${ }^{134}$

Suppressing acid secretion is believed to reduce the risk of ulcers associated with the regular use of NSAIDs. In patients who required continuous treatment with NSAIDs and who had ulcers or $>10$ erosions in their stomach or duodenum, omeprazole healed and prevented ulcers more effectively than did ranitidine. ${ }^{135}$ In these patients, maintenance therapy with omeprazole was associated with a lower rate of relapse and was better tolerated than misoprostol. ${ }^{136}$ In patients with a history of previous ulcer bleeding who took low-dose aspirin for 6 months, omeprazole and $\mathrm{H}$ pylori eradication were associated with similar rates of recurrent bleeding $(0.9 \%$ and $1.9 \%$, respectively), ${ }^{137}$ although clinically important differences between the two preventive strategies could not be excluded owing to the small sample size $(\mathrm{n}=250)$.

Two relatively small studies ${ }^{138,139}$ have challenged earlier guidelines that recommended the use of clopidogrel for patients who have major GI contraindications to aspirin, principally recent significant bleeding from a peptic ulcer or gastritis. Both studies enrolled patients who developed ulcer bleeding after the use of low-dose aspirin. In a study by Chan et al, ${ }^{138}$ after healing of ulcers and eradication of $H$ pylori, if present, 320 patients were randomly assigned to receive either clopidogrel $75 \mathrm{mg} / \mathrm{d}$ or aspirin $80 \mathrm{mg} / \mathrm{d}$ plus esomeprazole $20 \mathrm{mg}$ bid for 12 months. The cumulative incidence of recurrent bleeding was $8.6 \%$ (95\% CI, 4.1\%-13.1\%) among patients who received clopidogrel and $0.7 \%$ (95\% CI, 0\%-2.0\%) among those who received aspirin plus esomeprazole $(P=.001) .138$ In a study by Lai et al, ${ }^{139} 170$ patients with prior ulcer bleeding were randomly assigned to treatment with clopidogrel $75 \mathrm{mg} / \mathrm{d}$ or aspirin $100 \mathrm{mg} / \mathrm{d}$ and esomeprazole $20 \mathrm{mg} / \mathrm{d}$ for 1 year. The cumulative incidence of recurrent ulcer complications was $13.6 \%$ and $0 \%$, respectively (95\% CI for the difference, $6.3 \%-20.9 \%$; $P=.0019) .139$ The combination of esomeprazole and low-dose aspirin is superior to clopidogrel for the prevention of recurrent GI bleeding as is now recommended by the 2008 guidelines of the American College of Cardiology/American College of Gastroenterology/American Heart Association. ${ }^{140}$

Substantially less information is available about the risk of intracranial hemorrhage associated with aspirin use. In the Nurses' Health Study cohort of $\sim 79,000$ women aged 34 to 59 years, infrequent use of aspirin (1-6 tablets per week) was associated with a reduced risk of ischemic stroke, whereas high frequency use ( $\geq 15$ tablets per week) was associated with an increased risk of subarachnoid hemorrhage, particularly among older or hypertensive women. ${ }^{141}$ 
In the 2002 overview of the Antithrombotic Trialists' Collaboration, ${ }^{10}$ the overall absolute excess of intracranial hemorrhage due to aspirin therapy was less than one per 1,000 patients per year in trials that involved patients at high risk for cardiovascular events, with a somewhat higher risk in patients with cerebrovascular disease. The 2009 individual patient meta-analysis of primary prevention trials indicated that aspirin was associated with five additional hemorrhagic strokes per 1,000 among moderate-risk participants (risk of coronary event, $>1 \%$ per year) over 5 years (ie, $\sim 1 / 1,000$ per year) but substantially fewer events in low-risk participants. ${ }^{87}$

Low-dose aspirin therapy has not been reported to affect renal function or BP control, ${ }^{142}$ consistent with its lack of effect on renal prostaglandins ${ }^{143}$ primarily derived from constitutively expressed COX-2 in the kidney. ${ }^{84}$ Moreover, aspirin $75 \mathrm{mg} / \mathrm{d}$ did not affect BP or the need for antihypertensive therapy in intensively treated patients with hypertension. ${ }^{89}$ The suggestion that the use of aspirin and other antiplatelet agents is associated with reduced benefit in enalapriltreated patients with left ventricular systolic dysfunction $^{144}$ is not supported by the results of a large meta-analysis of MI trials. ${ }^{145}$ Similarly, no negative interaction occurred between angiotensin-converting enzyme (ACE) inhibition and the cardiovascular benefits of low-dose aspirin in intensively treated patients with hypertension. ${ }^{146}$ The ACE Inhibitors Collaborative Group performed a systematic overview of data from 22,060 patients included in six long-term randomized trials of ACE inhibitors to assess whether aspirin altered the effects of ACE inhibitor therapy on major clinical outcomes. ${ }^{147}$ Even though the results from these analyses cannot rule out the possibility of an interaction, they show unequivocally that even if aspirin is given, the addition of ACE inhibitor therapy produces substantial additional benefit in all major vascular outcomes. Therefore, in the absence of clear contraindications, concomitant use of aspirin and ACE inhibitors should be considered in all patients who are at high risk of major vascular events. ${ }^{147}$

\subsection{DiPYRIDAMOLE}

\subsection{Mechanism of Action}

Dipyridamole is a pyrimidopyrimidine derivative with vasodilator and antiplatelet properties. The mechanism of action of dipyridamole as an antiplatelet agent is controversial. ${ }^{148}$ Both inhibition of cyclic nucleotide phosphodiesterase (the enzyme that degrades cyclic adenosine monophosphate [AMP] to $5^{\prime}$-AMP, resulting in the intraplatelet accumulation of cyclic AMP, an inhibitor of platelet aggrega- tion) and blockade of the uptake of adenosine (which binds to $\mathrm{A}_{2}$ receptors, stimulates platelet adenyl cyclase, and increases cyclic AMP) have been suggested. Moreover, direct stimulation of $\mathrm{PGI}_{2}$ synthesis and protection against its degradation have been reported, although the dipyridamole concentrations required to produce these effects far exceed the low-micromolar plasma levels achieved after oral administration of conventional doses (100-400 mg/d). ${ }^{148}$ Dipyridamole also differentially inhibits the expression of critical inflammatory genes by plateletleukocyte aggregates. ${ }^{149}$

\subsection{Pharmacokinetics}

The absorption of dipyridamole from conventional formulations is quite variable and may result in low systemic bioavailability of the drug. A modifiedrelease formulation of dipyridamole with improved bioavailability has been developed in a combination pill with low-dose aspirin. ${ }^{150}$ Dipyridamole is highly protein bound to albumin, eliminated primarily by biliary excretion as a glucuronide conjugate, and is subject to enterohepatic recirculation. A terminal half-life of $10 \mathrm{~h}$ has been reported. This is consistent with the bid regimen used in recent clinical studies.

\subsection{Efficacy and Safety}

The clinical efficacy of immediate-release dipyridamole, alone or in combination with aspirin, was questioned on the basis of earlier randomized trials., ${ }^{3,151}$ As a result, the reformulated extended-release preparation was evaluated in the more recent ESPS-2, Aspirin Plus Dipyridamole Versus Aspirin Alone After Cerebral Ischaemia of Arterial Origin (ESPRIT), and Prevention Regimen for Effectively Avoiding Second Strokes (PRoFESS) randomized trials. In ESPS-2, the new preparation of dipyridamole was evaluated in 6,602 patients with prior stroke or TIA. ${ }^{40}$ This study showed that the addition of modifiedrelease dipyridamole ( $200 \mathrm{mg}$ bid) to aspirin $(25 \mathrm{mg}$ bid) was associated with a $22 \%$ relative risk reduction in major vascular events compared with aspirin alone. Headache was the most common adverse effect of dipyridamole.

In the ESPRIT trial, ${ }^{152} 2,739$ patients within 6 months of a TIA or minor stroke of presumed arterial origin were randomized to receive aspirin (30-325 mg/d) with or without dipyridamole (200 mg bid). Compared with aspirin alone, the primary outcome (a composite of major vascular events or major bleeding complications) was reduced by $20 \%$ with the combined treatment. Patients on aspirin plus dipyridamole discontinued trial medication almost 
three times more often than those on aspirin alone mainly because of headache. ${ }^{152}$

In the PRoFESS trial, ${ }^{153}$ 20,332 patients with recent ischemic stroke were randomized to receive the combination of aspirin ( $25 \mathrm{mg}$ bid) plus extendedrelease dipyridamole (200 $\mathrm{mg}$ bid) or clopidogrel ( $75 \mathrm{mg}$ once daily) for a mean of 2.5 years. The HR for the primary efficacy outcome (1.01; 95\% CI, $0.92-1.11$ ) failed to reach the prespecified noninferiority margin. Major hemorrhages occurred more frequently in those given aspirin plus extended-release dipyridamole than in patients treated with clopidogrel (HR, 1.15; 95\% CI, 1.00-1.32), and the combination was associated with an excess of intracranial hemorrhage (HR, 1.42; 95\% CI, 1.11-1.83).

A meta-analysis of six randomized trials involving 7,648 patients with a history of TIA or stroke in which stroke was reported as an outcome demonstrated that compared with aspirin alone (dose range, 50$1,300 \mathrm{mg} / \mathrm{d}$ ), the combination of aspirin (dose range, $50-1,300 \mathrm{mg} / \mathrm{d}$ ) plus dipyridamole reduced stroke by $23 \%$ (RR, 0.77; 95\% CI, 0.67-0.89), with no statistical evidence of heterogeneity. ${ }^{154}$ Consistent estimates were obtained from trials that used the immediaterelease preparation of dipyridamole (four trials) and those that used the extended-release preparation. A Cochrane review of 29 randomized trials involving 23,019 patients confirmed the superiority of the combination of aspirin plus dipyridamole over aspirin alone for prevention of vascular events in patients with a history of TIA or stroke but found no evidence of a benefit of the combination in studies involving patients with a history of coronary or peripheral arterial disease or in other high-risk patients. ${ }^{155}$

\subsection{Cilostazol}

\subsection{Mechanism of Action}

Cilostazol is a 2-oxoquinolone derivative that is reported to have vasodilatory and antiplatelet properties as well as antiproliferative effects, reducing smooth muscle cell proliferation and neointimal hyperplasia after endothelial injury. Cilostazol is a common cause of GI side effects, and headache occurs in up to one-fourth of patients within the first 2 weeks of starting treatment. Cilostazol is contraindicated in patients with heart failure because of the potential to trigger ventricular tachycardia, an effect that has been attributed to the increase in intracellular cyclic AMP, a mechanism that likely also accounts for the vasodilatory effects of cilostazol.

\subsection{Pharmacokinetics}

There is substantial variability in the absorption of orally administered cilostazol. Coadministration of food increases the rate and extent of drug absorption. Cilostazol is highly albumin bound and is extensively metabolized by cytochrome P450 (CYP450) enzymes, with excretion of metabolites in the urine. It has a half-life of $11 \mathrm{~h}$, and the half-life is prolonged in patients with severe renal impairment.

\subsection{Efficacy and Safety}

Meta-analyses of mainly small, open-label, placeboand active-controlled trials have demonstrated that cilostazol (50 mg bid or $100 \mathrm{mg}$ once daily) increases maximal and pain-free walking distance in patients with intermittent claudication, ${ }^{156}$ prevents thrombotic events in patients with peripheral arterial disease, ${ }^{157}$ and prevents restenosis and target vessel revascularization in patients undergoing stenting of coronary or peripheral arteries. ${ }^{158}$

The Cilostazol for Prevention of Secondary Stroke (CSPS-2) study evaluated the efficacy and safety of cilostazol (100 mg bid) compared with aspirin $(81 \mathrm{mg} / \mathrm{d})$ in 2,757 Japanese patients with recent stroke, using a noninferiority study design. 159 The mean duration of follow-up was 29 months. In an on-treatment analysis, the annual rate of recurrent stroke was $2.8 \%$ in patients randomized to receive cilostazol and $3.7 \%$ in those randomized to receive aspirin (HR, 0.74; 95\% CI, 0.56-0.98), which met the prespecified criterion for noninferiority. Consistent with the results of the placebo-controlled comparisons, which demonstrated no increase in bleeding with cilostazol, the annual rate of bleeding with cilostazol was lower than that with aspirin $(0.77$ and $1.78 \%$, respectively; HR, 0.46; 95\% CI, 0.30-0.71), although bleeding rates were unexpectedly low in both groups. Headache, diarrhea, palpitation, dizziness, and tachycardia were more frequent with cilostazol than with aspirin and led to an almost twofold higher rate of discontinuation of cilostazol ( $20 \%$ vs $12 \%$ ).

\subsection{THIENOPYRIDINES}

Ticlopidine, clopidogrel, and prasugrel represent three generations of oral thienopyridines that selectively inhibit ADP-induced platelet aggregation. The firstgeneration agent ticlopidine was limited by bone marrow toxicity and has largely been replaced by clopidogrel, which has become established as standard therapy across the spectrum of patients with ACS and in those undergoing percutaneous coronary intervention (PCI). However, clopidogrel also has limitations, including variable absorption; variable antiplatelet effects related, at least in part, to common polymorphisms in the genes that regulate the metabolic activation of clopidogrel; and a delayed onset and offset of action. Prasugrel, the third-generation thienopyridine, has a more rapid 
onset of action, is more potent than clopidogrel, and produces more consistent platelet inhibition. All three thienopyridines are prodrugs that must undergo metabolic activation through the hepatic CYP450 system to generate the active metabolites that inhibit the platelet P2Y12 receptor. Permanent inhibition of the platelet P2Y12 receptor by thienopyridines is consistent with the time-dependent, cumulative inhibition of ADP-induced platelet aggregation that occurs with repeated daily dosing of the slower-acting thienopyridines ticlopidine and clopidogrel and with the slow recovery of platelet function after drug withdrawal. ${ }^{160}$ Although thienopyridines can also suppress platelet aggregation induced by arachidonic acid, collagen, and thrombin, ${ }^{161,162}$ these inhibitory effects are attenuated or abolished by increasing the agonist concentration and are probably explained by blockade of ADP-mediated amplification of the platelet response to other agonists.

\subsection{Ticlopidine}

4.1.1 Pharmacokinetics: Up to $90 \%$ of a single oral dose of ticlopidine is rapidly absorbed. ${ }^{160}$ Plasma concentrations peak 1 to $3 \mathrm{~h}$ after a single oral dose of $250 \mathrm{mg}$. More than $98 \%$ of absorbed ticlopidine is reversibly bound to plasma proteins, primarily albumin. Ticlopidine is metabolized rapidly and extensively. A total of 13 metabolites have been identified in humans. Of these, only the 2-keto derivative of ticlopidine is more potent than the parent compound at inhibiting ADP-induced platelet aggregation. ${ }^{160}$ The apparent elimination half-life of ticlopidine is 24 to $36 \mathrm{~h}$ after a single oral dose and up to $96 \mathrm{~h}$ after 14 days of repeated dosing. ${ }^{160}$ The standard dosing regimen of ticlopidine is $250 \mathrm{mg}$ bid.

4.1.2 Efficacy and Safety: As a single agent, ticlopidine has been evaluated in patients with stroke, ${ }^{163}$ transient cerebral ischemia, ${ }^{164}$ unstable angina, ${ }^{165}$ MI, ${ }^{166}$ and intermittent claudication ${ }^{167-169}$ and in those undergoing aortocoronary bypass surgery. ${ }^{170}$ Ticlopidine was more effective than aspirin in reducing stroke in patients with transient cerebral ischemia or minor stroke ${ }^{164}$ (although there was no statistically significant difference in the combined outcome of stroke, MI, or death ${ }^{10}$ ); was as effective as aspirin in the treatment of patients with a recent MI ${ }^{166}$; was more effective than placebo in reducing the risk of the combined outcome of stroke, MI, or vascular death in patients with thromboembolic stroke ${ }^{163}$; was more effective than conventional antianginal therapy in reducing vascular death or MI in patients with unstable angina ${ }^{165}$; was more effective than placebo in reducing acute occlusion of coronary bypass grafts ${ }^{170}$; and was more effective than controls in improving walking distance ${ }^{168}$ and reducing vascular complica- tions in patients with peripheral arterial disease. ${ }^{167-169}$ The association of ticlopidine therapy with hypercholesterolemia and neutropenia (for which the reported rate of occurrence is $2.4 \%$ for a neutrophil count of $<1.2 \times 10^{9} / \mathrm{L}$ and $0.8 \%$ for a count of $<0.45 \times 10^{9} / \mathrm{L}$ ), and its comparative expense has reduced enthusiasm for this therapy as an alternative to aspirin in most situations. ${ }^{171}$ Ticlopidine has also been associated with thrombocytopenia, ${ }^{171}$ aplastic anemia, ${ }^{172}$ and thrombotic thrombocytopenic purpura (TTP). ${ }^{173}$ Ticlopidine has been approved for clinical use in patients with cerebral ischemia when aspirin has failed, cannot be tolerated, or is contraindicated, although this limitation does not apply in all countries where the drug is registered.

Several studies have demonstrated the superiority of the combination of ticlopidine plus aspirin compared with aspirin alone or aspirin plus warfarin in preventing thrombotic complications after coronary artery stent placement. ${ }^{174,175}$ Ticlopidine was routinely used in combination with aspirin in patients receiving coronary artery stents, but the superior safety profile of clopidogrel has resulted in the replacement of ticlopidine by clopidogrel as the standard of care after stent deployment. ${ }^{176}$ The risk of TTP associated with ticlopidine is estimated to be $0.02 \%$ in patients receiving the drug after stent placement. ${ }^{177}$ This compares with an incidence of $0.0004 \%$ in the general population. The mortality rate for this complication exceeds $20 \% .^{177}$

The role of ticlopidine in the current therapeutic armamentarium is uncertain because of the toxicities presented. In most jurisdictions, it has been largely replaced by clopidogrel.

\subsection{Clopidogrel}

4.2.1 Pharmacokinetics: Clopidogrel is rapidly absorbed and metabolized through a two-step process to generate a highly labile active metabolite ${ }^{178}$ that irreversibly binds to the platelet P2Y12 receptor when platelets pass through the liver. ${ }^{179}$ The main systemic metabolite of clopidogrel is the inactive carboxylic acid derivative SR 26334, which has a halflife of $\sim 8 \mathrm{~h}$. On repeated daily dosing of 50 to $100 \mathrm{mg}$ of clopidogrel in healthy volunteers, ADP-induced platelet aggregation was inhibited from the second day of treatment (25\%-30\% inhibition) and reached a steady state (50\%-60\% inhibition) after 4 to 7 days. Such a level of maximal inhibition was comparable to that achieved with ticlopidine $(500 \mathrm{mg} / \mathrm{d})$, although the antiplatelet effects of the latter was more delayed than that of clopidogrel. No appreciable differences in the maximum inhibitory effects produced by 50,75 , or $100 \mathrm{mg}$ of clopidogrel were noted in this study. ${ }^{180}$ As would be expected from these 
pharmacokinetic and pharmacodynamic features, a loading dose (eg, $300 \mathrm{mg}$ ) of clopidogrel results in more-rapid platelet inhibition than is achieved with the 75 -mg dose. ${ }^{181}$ After loading with $600 \mathrm{mg}$ of clopidogrel, the full antiplatelet effect of the drug was achieved after 2 to 4 h. ${ }^{182}$ Moreover, a loading dose of $600 \mathrm{mg}$ resulted in higher plasma concentrations of the active metabolite and the inactive carboxyl metabolite compared with a loading dose of $300 \mathrm{mg} .{ }^{183}$ Inhibition of ADP-induced platelet aggregation was also significantly greater with a 600-mg loading dose of clopidogrel compared with a 300-mg loading dose. ${ }^{183-185}$ The incremental antiplatelet effect of $900 \mathrm{mg}$ over $600 \mathrm{mg}$ of clopidogrel appears marginal ${ }^{183,185}$ possibly because of limited drug absorption. ${ }^{183}$

The active metabolite of clopidogrel has a pharmacodynamic pattern similar to that of aspirin; there is cumulative inhibition of platelet function with repeated daily administration of low doses. Platelet function does not return to normal until 7 to 10 days after the last dose of clopidogrel. Both the cumulative nature of the inhibitory effects and the slow rate of recovery of platelet thromboxane production (aspirin) or ADP-induced platelet aggregation (clopidogrel) are consistent with permanent inhibition of COX-1 and the P2Y12 receptor, respectively, by the active moieties of aspirin and clopidogrel (active metabolite). This also justifies a once-daily regimen for aspirin and clopidogrel in patients with normal rates of platelet turnover, despite the short half-life of both drugs in the circulation. It should be noted, however, that although aspirin currently is used at doses that represent a 2.5 - to 10 -fold excess over the 30 -mg dose necessary to fully inactivate platelet COX-1 activity on repeated daily dosing, ${ }^{28,35}$ clopidogrel is used at doses that produce only partial inhibition of the P2Y12 receptor. Thus, the main determinants of the interindividual variability in the antiplatelet effects of the two drugs are also likely to be substantially different (Table 6).

Table 6-Main Determinants of the Interindividual Variability in the Antiplatelet Effects of Aspirin and Clopidogrel

\begin{tabular}{lcc}
\hline \hline Determinant & Aspirin & Clopidogrel \\
\hline $\begin{array}{l}\text { Dependence on systemic bioavailability } \\
\begin{array}{l}\text { Dependence on liver metabolism to active } \\
\text { moiety }\end{array}\end{array}$ & No & Yes \\
$\begin{array}{l}\text { Ratio of recommended dose: minimum } \\
\text { effective dose for full pharmacodynamic } \\
\text { effect }\end{array}$ & $2-3$ & 1 \\
$\begin{array}{l}\text { Relevance of pharmacodynamic } \\
\text { interactions at the target site }\end{array}$ & Yes & ? \\
$\begin{array}{l}\text { Relevance of genetic polymorphisms } \\
\text { affecting drug absorption or metabolism }\end{array}$ & No & Yes \\
\hline
\end{tabular}

4.2.2 High On-Treatment Platelet Reactivity (Clopidogrel Resistance): Numerous studies have demonstrated variable levels of platelet P2Y12 receptor inhibition in patients treated with clopidogrel and an increased risk of thrombotic events in those with high on-treatment platelet reactivity. ${ }^{186}$ High on-treatment platelet reactivity is reported to occur in about onethird of those prescribed clopidogrel and has been associated with a 1.5-fold to fivefold increased risk of thrombosis.

Estimates of the prevalence of high platelet reactivity in patients prescribed clopidogrel vary according to comorbidities (eg, diabetes, dyslipidemia), concomitant therapies (lipophilic statins, eg, simvastatin and atorvastatin; proton pump inhibitors, eg, omeprazole; and calcium channel blockers), and the test and cutoffs used to define high reactivity. Particular attention has focused on the mechanisms responsible for insufficient active metabolite generation as an explanation for high platelet reactivity in patients prescribed clopidogrel. Variable levels of active metabolite generation can be caused by smoking, drugs that stimulate or inhibit CYP450 isoenzymes (2C19, 1A2, 2B6, 2C9, 3A4) involved in the conversion of clopidogrel to its active metabolite and genetic polymorphisms involving CYP450 isoenzymes and ABCB1, the p-glycoprotein efflux transporter gene involved in GI absorption of clopidogrel. ${ }^{186}$

A reduced laboratory response to clopidogrel has been observed following coadministration of CYP3A4metabolized statins ${ }^{187}$ and CYP2C19-metabolized proton pump inhibitors, ${ }^{188}$ but the clinical relevance of these pharmacodynamic interactions remains uncertain because observational studies and post hoc analyses of randomized trials have yielded conflicting results. ${ }^{189-194}$ In the COGENT (Clopidogrel and the Optimization of Gastrointestinal Events) trial, 3,861 patients with an indication for dual antiplatelet therapy were randomly assigned to receive omeprazole or placebo. ${ }^{191}$ Omeprazole reduced the rates of GI events, including GI bleeding, by $>60 \%$, but the primary vascular outcome, a composite of MI, revascularization, stroke, or cardiovascular death, occurred in a similar proportion of patients in each treatment group (HR, 0.99; 95\% CI, 0.68-1.44). These results provide no evidence for a clinically important interaction between omeprazole and clopidogrel. ${ }^{191}$

Multiple observational studies have demonstrated an association between loss-of-function polymorphisms involving CYP2C19 and the risk of thrombotic events. In an individual patient meta-analysis of nine such studies involving 9,685 patients with ACS or undergoing PCI, Mega and colleagues ${ }^{195}$ demonstrated a significantly increased risk of MI, stroke, or cardiovascular death in carriers compared with noncarriers of one (HR, 1.55; 95\% CI, 1.11-2.17) and two (HR, 1.76; 
95\% CI, 1.24-2.50) reduced-function CYP2C19 alleles. The greatest effect of carriage of the loss-of-function alleles was on the incidence of stent thrombosis. Overall, $71.5 \%$ of subjects included in the trials were noncarriers, $26.3 \%$ had one reduced-function CYP2C19 allele, and 2.2\% had two reduced-function CYP2C19 alleles.

In contrast to the findings of observational studies, ${ }^{195}$ genetic analyses of three randomized trials, Study of Platelet Inhibition and Patient Outcomes (PLATO) and CURE in patients with ACS and ACTIVE A in patients with atrial fibrillation, did not demonstrate an interaction between CYP2C19 loss-of-function carrier status and randomized clopidogrel treatment of any outcome, including stent thrombosis. ${ }^{196,197}$ In the PLATO genetics study involving 10,285 patients with ACS randomized to receive ticagrelor or clopidogrel, estimates of relative risk for primary outcome of MI, stroke, or cardiovascular death were similar irrespective of CYP2C19 genotype (interaction $P=.46$ ), and likewise, no interaction was found for ABCB1 genotype or for the gain-of-function CYP2C19*17 allele. ${ }^{196}$ In the CURE genetics study involving 5,059 patients with ACS randomized to receive clopidogrel or placebo, the effect of clopidogrel in reducing the rate of the primary efficacy outcome of MI, stroke, or cardiovascular death was similar in patients who were heterozygous or homozygous for loss-of-function alleles and in those who were not carriers of these alleles. ${ }^{197}$ In contrast, carriers of gain-offunction alleles derived more benefit from clopidogrel treatment compared with placebo than did noncarriers, although this finding was only nominally significant (interaction $P=.02$ ). Among 1,156 genotyped patients with atrial fibrillation in the ACTIVE A trial, there was no evidence of an interaction with respect to either efficacy or bleeding between CYP2C19 genotype and study treatment. ${ }^{197}$

One proposed explanation for the discrepant findings of observational and randomized clopidogrel genetic studies is that only $14.5 \%$ of patients in the CURE trial underwent PCI, and the ACTIVE A trial enrolled patients with $\mathrm{AF}$ at relatively low risk of thrombotic events. ${ }^{198}$ However, this explanation cannot account for lack of a significant interaction between CYP2C19 loss-of-function polymorphisms and randomized clopidogrel treatment in the PLATO trial, which included high-risk patients with ACS of whom two-thirds underwent PCI. ${ }^{196}$ An alternative potential explanation is that the association between carriage of a loss-of-function allele and outcome is confounded or that loss-of-function alleles have pleiotropic effects (ie, independent of their effects on the levels of the active metabolite of clopidogrel) on clinical outcome.

As is the case for high on-treatment platelet reactivity in patients prescribed aspirin, there currently is no evidence to support the use of platelet function or genetic testing to individualize antiplatelet therapy. The Gauging Responsiveness With a Verify Now Assay-Impact on Thrombosis and Safety (GRAVITAS) trial found no evidence of reduced cardiovascular outcomes or stent thrombosis when double-dose clopidogrel was given to patients with high residual platelet reactivity after implantation of a drug-eluting stent despite aspirin plus usual-dose clopidogrel.199 Several trials currently under way are testing the hypothesis that adjusting therapy in response to the results of platelet function testing can improve clinical outcomes. ${ }^{200}$ Ongoing trials are also evaluating the possible benefit of a genotype-guided strategy for the management of patients at risk for poor outcomes either because they have already had an adverse event (eg, stent thrombosis) or because of other highrisk characteristics, such as diabetes mellitus, chronic renal failure, or angiographic high-risk features. ${ }^{198}$

4.2.3 Efficacy and Safety: The clinical development of clopidogrel was unusual because the phase 2 studies were limited and its approval was based on a single, large phase 3 trial, which compared the efficacy and safety of clopidogrel $(75 \mathrm{mg} / \mathrm{d})$ with those of aspirin (325 mg/d). ${ }^{201}$ The Clopidogrel vs Aspirin in Patients at risk for Ischemic Events (CAPRIE) trial included three groups of patients at increased risk of recurrent ischemic events, with each group involving $\sim 6,400$ patients: those who had experienced a recent stroke, those with a recent MI, and those with symptomatic peripheral arterial disease. Compared with aspirin in the overall CAPRIE study population of 19,185 high-risk patients, clopidogrel reduced the relative risk of MI, ischemic stroke, or vascular death by $8.7 \%$ (95\% CI, 3\%-65\%) and the absolute risk by $0.51 \%$.

Both clopidogrel and medium-dose aspirin therapy were well tolerated in the CAPRIE study. ${ }^{201}$ The incidence of early permanent discontinuation of study drug due to adverse events was $12 \%$ in both groups. Similarly, the overall incidence of hemorrhagic events was $9.3 \%$ in both groups. No excess neutropenia was found in the clopidogrel group, and the incidence of thrombocytopenia was identical in the clopidogrel and aspirin groups. On the basis of these findings, clopidogrel has been approved for the reduction of atherosclerotic events in patients with recent stroke, recent MI, or established peripheral arterial disease. TTP is rare but can occur after the initiation of clopidogrel therapy; when TTP occurs, its onset is usually within 2 weeks of initiation of treatment. ${ }^{202}$

Because clopidogrel and aspirin act on distinct and complementary pathways of platelet activation, combination therapy has been evaluated in high-risk clinical settings. ${ }^{203-208}$ The CURE trial ${ }^{208}$ randomly assigned 12,562 patients with ACS without ST-segment elevation 
who presented within $24 \mathrm{~h}$ of symptom onset to receive clopidogrel (300-mg loading dose followed by $75 \mathrm{mg}$ once daily) or placebo in addition to aspirin (75$325 \mathrm{mg} / \mathrm{d}$ ) for 3 to 12 months. After a mean duration of treatment of 9 months, the primary outcome (a composite of cardiovascular death, nonfatal MI, or stroke) occurred in $9.3 \%$ of the patients in the clopidogrel group and $11.4 \%$ of those given placebo (RR, 0.80; 95\% CI, $0.72-0.90 ; P<.001)$. The benefit of clopidogrel was apparent within the first 30 days after randomization and remained constant during the 12 months of the study. There were significantly more patients with major bleeding in the clopidogrel group than in the placebo group $(3.7 \%$ vs $2.7 \%$; $P=.001)$.

The clinical benefit of dual antiplatelet therapy over aspirin alone has been confirmed in patients undergoing PCI (Clopidogrel for the Reduction of Events During Observation [CREDO] ${ }^{207}$ and in those presenting with an acute ST-segment elevation MI within $12 \mathrm{~h}$ (Clopidogrel and Metoprolol Myocardial Infarction Trial [COMMIT]) ${ }^{204}$ to $24 \mathrm{~h}$ (Clopidogrel as Adjunctive Reperfusion Therapy [CLARITY] trial ${ }^{206}$ after the onset of symptoms. In the COMMIT trial, ${ }^{204}$ the addition of clopidogrel $(75 \mathrm{mg} / \mathrm{d})$ to aspirin $(162 \mathrm{mg} / \mathrm{d})$ reduced mortality and major vascular events in the hospital by $9 \%$ (95\% CI, 3\%-14\%), corresponding to nine fewer events per 1,000 patients with MI treated for $\sim 2$ weeks. Overall, when all transfused, fatal, or cerebral bleeds were considered, there was no significant excess risk associated with the use of clopidogrel during the scheduled treatment period $(0.58 \%$ clopidogrel plus aspirin vs $0.55 \%$ aspirin alone, $P=.59$ ), nor was there any excess of major bleeds in patients aged $>70$ years or in those given fibrinolytic therapy before randomization. ${ }^{204}$ Clopidogrel, however, was associated with a small, but significant excess of 4.7 (95\% CI, 1.4-8.0) minor bleeds per 1,000 patients treated. Taking major and minor bleeds together, there was no apparent trend with respect to age in the excess risk of bleeding. ${ }^{204}$ Factors that may have contributed to the remarkable safety of dual antiplatelet therapy in the COMMIT trial include the lack of a loading dose of clopidogrel, the uniform use of low-dose aspirin (162 mg/d), and the short duration of treatment.

Evidence for a more rapid onset of action and greater platelet inhibition with the use of a $600-\mathrm{mg}$ rather than a 300-mg loading dose of clopidogrel ${ }^{185}$ and growing concern about the possibility that a substantial proportion of patients achieve suboptimal inhibition of platelet function with conventional doses of clopidogrel prompted the CURRENT-OASIS 7 trial. This two-by-two factorial study, which enrolled 25,086 patients with ACS who were referred for an invasive management strategy, randomized such patients to receive either double-dose clopidogrel (a 600-mg loading dose on day 1 followed by $150 \mathrm{mg} / \mathrm{d}$ for 6 days and $75 \mathrm{mg} / \mathrm{d}$ thereafter) or standard-dose clopidogrel (a 300-mg loading dose and $75 \mathrm{mg} / \mathrm{d}$ thereafter) and either higher-dose aspirin (300-325 mg/d) or lower-dose aspirin (75-100 mg/d). The results of the aspirin dose comparison have been reviewed earlier. In the clopidogrel dose comparison, the rates of the primary outcome of MI, stroke, or vascular death were similar in patients receiving double-dose compared with standard-dose clopidogrel $(4.2 \%$ vs $4.4 \%$; HR, 0.94; 95\% CI, 0.83-1.06; $P=.30$ ), but in the 17,263 patients who underwent PCI, double-dose clopidogrel reduced stent thrombosis $(1.6 \%$ vs $2.3 \%$; HR, 0.68 ; 95\% CI, $0.55-0.85 ; P=.001)$ at the cost of an increase in major bleeding (2.5\% vs $2.0 \%$; $\mathrm{HR}$, 1.24; 95\% CI, 1.05-1.46). ${ }^{209}$ These results suggest that there is a benefit of more rapid and complete platelet inhibition with double-dose clopidogrel during the acute phase in patients presenting with ACS.

In contrast to the consistent finding of a favorable benefit/risk profile of dual antiplatelet therapy in patients with ACS, ${ }^{204,206,208}$ the same strategy was not proven successful when compared with aspirin alone in stable patients at high risk for atherothrombotic events $^{203}$ or with clopidogrel alone in patients after a recent ischemic stroke or TIA. ${ }^{205}$ Although there might be mechanistic reasons underlying this apparent heterogeneity in treatment effects, it is important to emphasize that the size of the additional benefit associated with dual antiplatelet therapy compared with aspirin alone in patients with ACS is only a fraction (about one-third) of the benefit associated with aspirin compared with no antiplatelet therapy in this population. Perhaps more importantly, both the CURE $^{208}$ and the COMMIT ${ }^{204}$ investigators tested realistic hypotheses of relative risk reduction $(17 \%$ and $10 \%$, respectively) and observed reductions (20\% and $9 \%$, respectively) that were consistent with these conservative estimates. In contrast, both the Management of Atherothrombosis With Clopidogrel in High Risk Patients (MATCH) ${ }^{205}$ and the Clopidogrel for High Atherothrombotic Risk and Ischemic Stabilization, Management, and Avoidance (CHARISMA) ${ }^{203}$ investigators tested overly optimistic expectations of risk reduction and actually observed only a fraction (approximately one-third to one-half) of the expected benefit.

The combination of clopidogrel and aspirin has also been compared with oral anticoagulation with a vitamin $\mathrm{K}$ antagonist $\mathrm{t}^{105}$ and with aspirin alone ${ }^{106}$ in the ACTIVE trial program. The primary outcome in both trials was the composite of stroke, non-CNS systemic embolism, MI, or vascular death. The 6,706-patient ACTIVE W trial was stopped early by the data monitoring committee because of clear evidence of superiority of warfarin over the combination 
of clopidogrel plus aspirin for the prevention of major vascular events $(3.9 \%$ vs $5.6 \%$ per year; RR, 1.44 ; 95\% CI, 1.18-1.76), with similar rates of major bleeding. ${ }^{105}$ The ACTIVE A trial, which included patients with atrial fibrillation who were deemed ineligible for warfarin therapy, demonstrated superiority of the combination of clopidogrel plus aspirin over aspirin alone for the prevention of major vascular events (6.8\% vs $7.6 \%$ per year; RR, $0.89 ; 95 \%$ CI, 0.81-0.98). The difference was primarily due to a $28 \%$ relative reduction in the rate of stroke with clopidogrel, but this was achieved at a cost of an increase in major bleeding $(2.0 \%$ vs $1.3 \%$ per year; RR, 1.57; 95\% CI, 1.29-1.92), including a two per 1,000 per year increase in intracranial bleeding. ${ }^{106}$ The results of the ACTIVE trial program confirm the superiority of anticoagulants over antiplatelet therapy for stroke prevention in patients with atrial fibrillation but at the same time establish the superiority of dual antiplatelet therapy with clopidogrel plus aspirin over aspirin alone for this indication, thereby supporting a mechanistic role of platelets in cardioembolic stroke.

\subsection{Prasugrel}

4.3.1 Pharmacokinetics: Prasugrel is rapidly absorbed after oral ingestion and is rapidly converted to its active metabolite, which reaches peak concentrations within $30 \mathrm{~min}$ of dosing. Absorption is unaffected by food. The active metabolite has a half-life of $\sim 4 \mathrm{~h}$, and renal excretion is the major route for elimination of the metabolites. ${ }^{210}$ The prasugrel active metabolite is converted to inactive metabolites by S-methylation and cysteine conjugation.

Initial pharmacological studies with prasugrel in healthy individuals ${ }^{211}$ and in patients with stable coronary artery disease ${ }^{212}$ showed that prasugrel has a more rapid onset of action than clopidogrel and achieves more consistent and complete inhibition of ADPinduced platelet aggregation. ${ }^{211,212}$ The more rapid onset of action of prasugrel may in part reflect the hepatic conversion to its active metabolite by CYP 450 enzymes in a single step, which contrasts with that of clopidogrel, which undergoes a two-step hepatic conversion process. ${ }^{213}$ No evidence exists that polymorphisms in CYP2C19 or the concomitant use of proton pump inhibitors interfere with the metabolism of prasugrel. ${ }^{211,214}$

4.3.1 Efficacy and Safety: The efficacy and safety of prasugrel have been compared with those of clopidogrel in the Trial to Assess Improvement in Therapeutic Outcomes by Optimizing Platelet Inhibition with Prasugrel-Thrombolysis in Myocardial Infarction 38 (TRITON-TIMI 38). ${ }^{214}$ In this trial, which involved 13,608 patients with ACS scheduled to undergo PCI, prasugrel (60-mg loading dose followed by $10 \mathrm{mg} / \mathrm{d}$ ) was compared with standard-dose clopidogrel (300-mg loading dose followed by $75 \mathrm{mg} / \mathrm{d}$ ). Compared with clopidogrel, prasugrel reduced the composite primary outcome of MI, stroke, or cardiovascular death $(9.9 \%$ vs $12.1 \%$; HR, 0.81; 95\% CI, 0.73-0.90) as well as stent thrombosis $(1.1 \%$ vs $2.4 \%, P<.001)$ but did not reduce overall mortality and increased major, life-threatening, and fatal bleeding. Secondary analyses suggested that the greatest benefits of prasugrel occurred in patients with ST-segment-elevation MI, a setting in which rapid and complete platelet inhibition is critical, and in those with diabetes, a patient population consistently documented to have high on-treatment platelet reactivity despite therapy with both aspirin and clopidogrel. The excess of bleeding with prasugrel reflects its more rapid onset of action; its higher potency; and, possibly, its more consistent antiplatelet effects. The FDA approval of prasugrel came with a boxed warning regarding the risk of significant or fatal bleeding. The drug is contraindicated in patients with active bleeding or with a history of stroke. The Targeted Platelet Inhibition to Clarify the Optimal Strategy to Medically Manage Acute Coronary Syndromes (TRILOGY ACS) trial is evaluating whether a more favorable benefit/risk ratio can be obtained by reducing the dose of prasugrel. ${ }^{215}$

\subsection{GLYCOPROTEIN IIB/IIIA ANTAgONISTS}

The pharmacologic characteristics of the three approved IV glycoprotein IIb/IIIa (GpIIb-IIIa) inhibitors abciximab, tirofiban, and eptifibatide are summarized in Table 7.

\subsection{Abciximab}

Abciximab is a humanized version of a Fab fragment of a murine antibody directed against GpIIb-IIIa. Blockade of GpIIb-IIIa with abciximab produces a

Table 7-Comparison of Glycoprotein IIb/IIIa Inhibitors in Clinical Use

\begin{tabular}{|c|c|c|c|}
\hline & Abciximab & Tirofiban & Eptifibatide \\
\hline Structure & $\begin{array}{c}\text { Antibody Fab } \\
\text { fragment }\end{array}$ & Nonpeptide & $\begin{array}{l}\text { Cyclic } \\
\text { heptapeptide }\end{array}$ \\
\hline Molecular weight & $48 \mathrm{kDa}$ & $<1 \mathrm{kDa}$ & $<1 \mathrm{kDa}$ \\
\hline Onset & Rapid & Rapid & Rapid \\
\hline $\begin{array}{l}\text { Reversibility of platelet } \\
\text { inhibitory effects }\end{array}$ & Slow & Rapid & Rapid \\
\hline Drug half-life & $10-30 \mathrm{~min}$ & $2 \mathrm{~h}$ & $2.5 \mathrm{~h}$ \\
\hline Excretion & Unknown & $\begin{array}{l}40 \%-70 \% \\
\text { renal }\end{array}$ & $50 \%$ renal \\
\hline
\end{tabular}


phenotype similar to that of Glanzmann thrombasthenia. ${ }^{216}$ Approximately 40,000 antibody molecules bind to the surface of each platelet, but because they likely bind in a bivalent fashion, there are probably 80,000 GpIIb-IIIa receptors per platelet. ${ }^{217}$ Platelet aggregation is significantly inhibited at antibody doses that decrease the number of available receptors to $<50 \%$ of normal. Platelet aggregation is nearly completely abolished with $\sim 80 \%$ receptor blockade, but the bleeding time is only mildly affected at this level of receptor blockade. It is only with $>90 \%$ receptor blockade that the bleeding time becomes markedly prolonged. ${ }^{217}$

After IV bolus administration, pharmacokinetic data indicate that free plasma abciximab concentrations decrease rapidly (initial half-life of about $30 \mathrm{~min}$ ), reflecting the rapid binding of the antibody to GpIIb-IIIa, with $\sim 65 \%$ of the antibody becoming attached to platelets in the circulation and spleen. ${ }^{218}$ A bolus dose of $0.25 \mathrm{mg} / \mathrm{kg}$ blocked $>80 \%$ of the receptors and reduced platelet aggregation in response to $20 \mu \mathrm{mol} / \mathrm{L}$ ADP to $<20 \%$ of baseline. ${ }^{218}$ Peak effects on receptor blockade, platelet aggregation, and bleeding time were observed at $2 \mathrm{~h}$, the first sampling time. This was followed by gradual recovery of platelet function, with bleeding times returning to near-normal values by $12 \mathrm{~h} .{ }^{218}$ ADP-induced platelet aggregation returns to at least $50 \%$ of the baseline level within $24 \mathrm{~h}$. Small amounts of abciximab can be detected on circulating platelets for up to 14 days, presumably reflecting antibody redistribution from platelet to platelet. ${ }^{219}$

The receptor blockade, inhibition of platelet aggregation, and prolongation of the bleeding time achieved with a $0.25-\mathrm{mg} / \mathrm{kg}$ bolus dose of abciximab could be maintained by administering the drug at a dose of $10 \mu \mathrm{g} / \mathrm{min}$ over $12 \mathrm{~h} .{ }^{218}$ This regimen was chosen for the Evaluation of 7E3 for the Prevention of Ischaemic Complications (EPIC) trial, ${ }^{220}$ which demonstrated the efficacy of abciximab when added to conventional antithrombotic therapy for reducing the incidence of ischemic events in patients undergoing percutaneous transluminal coronary angioplasty (PTCA). Subsequently, the dose was modified to $0.125 \mu \mathrm{g} / \mathrm{kg}$ per min (to a maximum of $10 \mu \mathrm{g} / \mathrm{min}$ ) to adjust for differences in body weight.

Thrombocytopenia occurs in $1 \%$ to $2 \%$ of patients treated with abciximab. The risk of thrombocytopenia appears to be increased with abciximab readministration. ${ }^{221,222}$ Typically, the decrease in platelet count occurs within $24 \mathrm{~h}$ of initiation of treatment but may begin to fall as early as $2 \mathrm{~h}$ after treatment starts. Consequently, the abciximab package insert specifies that a platelet count should be obtained 2 to $4 \mathrm{~h}$ after initiating therapy. The thrombocytopenia is believed to be antibody mediated. ${ }^{223}$ In most cases, the thrombocytopenia resolves when the drug is stopped. If necessary, platelet transfusions can be given. .20,224,225 $^{2}$

\subsection{Tirofiban}

Tirofiban is a nonpeptide tyrosine derivative that selectively binds to GpIIb-IIIa. ${ }^{226,227}$ The plasma halflife of tirofiban is 1.5 to $2 \mathrm{~h}$, and both renal and biliary excretion contribute to tirofiban clearance, with unchanged tirofiban found in urine and feces. ${ }^{228}$ Dose adjustment is required in patients with renal insufficiency but not in patients with hepatic disease.

In a pilot study, 73 patients undergoing PTCA were treated with aspirin, heparin, and bolus doses of tirofiban of 5,10 , or $15 \mu \mathrm{g} / \mathrm{kg}$ followed by an infusion of $0.05,0.10$, or $0.15 \mu \mathrm{g} / \mathrm{kg}$ per min, respectively. ${ }^{229}$ Tirofiban produced rapid and dose-dependent inhibition of platelet aggregation and prolonged the bleeding time. After stopping tirofiban, platelet aggregation recovered to $50 \%$ of the baseline value within $4 \mathrm{~h}$.

In patients with a creatinine clearance $<30 \mathrm{~mL} / \mathrm{min}$, the half-life of tirofiban is prolonged more than threefold. ${ }^{230}$ Although the manufacturer recommends a $50 \%$ reduction in both the bolus and the infusion doses in such patients, the pharmacokinetic basis for this recommendation has been challenged. ${ }^{230}$ In the Platelet Receptor Inhibition in Ischemic Syndrome Management in Patients Limited by Unstable Signs and Symptoms (PRISM-PLUS) trial, the 40 patients with a creatinine clearance $<30 \mathrm{~mL} / \mathrm{min}$ had an increased risk of bleeding. ${ }^{231}$

Severe, but reversible thrombocytopenia has been reported in a small percentage of patients treated with tirofiban. Thrombocytopenia is believed to be immune mediated; tirofiban binding induces a conformational change in GpIIb-IIIa, and antibodies are generated against the newly exposed epitope. ${ }^{225,232}$ No data are available on the safety of tirofiban readministration, but high antibody titers have been found in patients who developed thrombocytopenia after tirofiban exposure. ${ }^{233}$

\subsection{Eptifibatide}

Eptifibatide is a synthetic disulfide-linked cyclic heptapeptide. It is patterned after the KGD sequence found in the snake venom disintegrin obtained from Sistrurus miliarius barbouri (barbourin), and has high specificity for GpIIb-IIIa. ${ }^{234,235}$ Although preliminary reports have suggested that eptifibatide produces less prolongation of the bleeding time than other GpIIb-IIIa inhibitors at doses producing comparable inhibition of platelet aggregation, it is likely that collection of the blood samples into citrate resulted in an overestimate of the inhibitory effects of eptifibatide, ${ }^{236}$ 
Because the drug is cleared by the kidneys, patients with renal impairment exhibit prolonged inhibition of platelet function after receiving eptifibatide. The proper dose of eptifibatide in patients with modest to moderate renal insufficiency is uncertain. ${ }^{230}$ In the ESPRIT trial, patients with a creatinine clearance $<60 \mathrm{~mL} / \mathrm{min}$ had increased major and minor bleeding rates compared with those with higher creatinine clearances, and eptifibatide treatment increased major and minor bleeding in both groups of patients. ${ }^{237}$

With an infusion rate of $2 \mu \mathrm{g} / \mathrm{kg}$ per min, the steady-state level of eptifibatide is $\sim 1,900 \mathrm{ng} / \mathrm{mL}$, suggesting that $>50$ molecules of eptifibatide bind to each GpIIb-IIIa. ${ }^{238}$ Consequently, platelet transfusion may not reverse the effects of the drug. ${ }^{239}$ Based on the results of phase 2 studies, two bolus doses of $180 \mu \mathrm{g} / \mathrm{kg}$ per min given $10 \mathrm{~min}$ apart followed by a $2 \mu \mathrm{g} / \mathrm{kg}$ per min infusion was selected for the phase 3 trials.

Eptifibatide treatment has been associated with thrombocytopenia, ${ }^{240,241}$ and an immunologic mechanism has been identified in some patients. ${ }^{233}$ No data are available about the safety of reinfusing eptifibatide, but high levels of antibody have been found in patients who develop thrombocytopenia after reexposure to eptifibatide. ${ }^{233}$

\subsection{Efficacy and Safety of IV GpIIb-III a Antagonists}

5.4.1 ACS, ST-Segment Elevation MI, and Coronary Revascularization: The efficacy and safety of GpIIb-IIIa antagonists were initially evaluated in patients undergoing PCI. The first of these phase 3 trials, the EPIC trial, ${ }^{220}$ resulted in approval of abciximab in 1994 for PCI patients at high risk of developing ischemic complication. Eptifibatide was studied in the Integrilin to Minimise Platelet Aggregation and Coronary Thrombosis-II (IMPACT-II) ${ }^{242}$ and ESPRIT trials, ${ }^{243,244}$ whereas tirofiban was studied in the Randomized Efficacy Study of Tirofiban for Outcomes and Restenosis (RESTORE) trial. ${ }^{245}$ Although neither the IMPACT-II nor the RESTORE trials achieved their predefined efficacy end points, there was a positive trend in each case. Eptifibatide received approval from the FDA for PCI in 1998 based on data from the IMPACT-II and PURSUIT (Platelet Glycoprotein IIb/IIIa in Unstable Angina: Receptor Suppression Using Integrilin Therapy) trials, and the dosing was modified based on the efficacy demonstrated in the ESPRIT trial. ${ }^{243,244}$ The CAPTURE (Chimeric c7E3 AntiPlatelet Therapy in Unstable Angina Refractory to Standard Treatment trial) ${ }^{246}$ demonstrated the efficacy of an 18- to 24-h infusion of abciximab prior to PCI in patients with unstable angina refractory to conventional antithrombotic and antianginal therapy. The Evaluation in
PTCA to Improve Long-term Outcome with Abciximab Glycoprotein IIb/IIIa Blockade (EPILOG) trial224 demonstrated the efficacy of abciximab in a broad patient population undergoing PCI, not just high-risk patients as enrolled in the EPIC and CAPTURE trials. The Evaluation of Platelet IIb/IIIa Inhibitor for Stenting Trial (EPISTENT) demonstrated that abciximab decreases the frequency of ischemic complications associated with stent insertion during the first 30 days. ${ }^{247}$ Furthermore, the 1-year mortality difference was statistically significant between stent alone $(2.4 \%)$ and stent plus abciximab (1\%), and this mortality difference was sustained for longer periods of time. ${ }^{248}$ Both abciximab and stenting were studied in the Controlled Abciximab and Device Investigation to Lower Late Angioplasty Complications (CADILLAC) trial, which enrolled patients with MI. ${ }^{249}$ In this group of patients who appeared to be at relative low risk, abciximab had a beneficial effect in the PTCA group but did not affect death or reinfarction in the stent group. ${ }^{249}$

Abciximab was compared with tirofiban in patients undergoing PCI in the Do Tirofiban and ReoPro Give Similar Efficacy Trial (TARGET). Abciximab treatment was found to be associated with a statistically significant lower rate of ischemic complications after 30 days. ${ }^{250,251}$

A series of randomized clinical trials conducted by the ISAR (Intracoronary Stenting and Antithrombotic Regimen) group have reexamined the efficacy and safety of GpIIb-IIIa blockade in a broad range of patients undergoing PCI who also were receiving aspirin and clopidogrel. $252-255$ Using a $600-\mathrm{mg}$ clopidogrel loading dose given at least $2 \mathrm{~h}$ prior to $\mathrm{PCI}$ in all patients, the ISAR investigators evaluated the effects of adjunctive abciximab in low- to intermediate-risk patients, ${ }^{254}$ in patients undergoing revascularization of small-diameter vessels, ${ }^{252}$ in patients with diabetes mellitus, ${ }^{255}$ and in patients with non-STsegment elevation ACS. ${ }^{253}$ In stable patients undergoing elective PCI, pretreatment with $600 \mathrm{mg}$ of clopidogrel provides platelet inhibition sufficient to enable a safe procedure without the need for GpIIbIIIa blockade. ${ }^{252,254,255}$ However, the same abciximab regimen was associated with a statistically significant $25 \%$ relative risk reduction in the 30 -day combined end-point of death, MI, or urgent target vessel revascularization in patients with ACS.253 Although the additional benefit of GpIIb-IIIa blockade appeared to be confined to patients with an elevated troponin level $(>0.03 \mu \mathrm{g} / \mathrm{L})$, the $P$ value for the interaction was not statistically significant.

Randomized trials have examined the efficacy and safety of tirofiban, lamifiban (a nonpeptide GpIIb-IIIa blocker whose development has been discontinued), eptifibatide, and abciximab in patients 
with ACS without persistent ST-segment elevation randomized to receive a GpIIb-IIIa antagonist or placebo in addition to conventional antithrombotic therapy. ${ }^{240,256-259}$ These studies demonstrated a $0 \%$ to $27 \%$ relative risk reduction in MI or death at 30 days. Both eptifibatide and tirofiban have received approval from the FDA for the treatment of ACS, including patients who are to be managed medically and those undergoing PCI. However, in the Global Utilization of Strategies to Open Occluded Arteries (GUSTO) IV-ACS trial, ${ }^{256}$ abciximab for $24 \mathrm{~h}(0.25$-mg/kg bolus followed by a $0.125-\mu \mathrm{g} / \mathrm{kg}$ per min infusion) or $48 \mathrm{~h}$ was not beneficial as first-line medical treatment in patients with ACS. A meta-analysis of all major randomized clinical trials of GpIIb-IIIa antagonists in patients with ACS who were not routinely scheduled to undergo early coronary revascularization suggests a $9 \%$ reduction in the odds of death or MI at 30 days. ${ }^{260}$ However, the true size of the additional benefit resulting from short-term, high-grade blockade of GpIIb-IIIa combined with standard antithrombotic therapy is somewhat uncertain because the $95 \%$ CI ranged from $2 \%$ to $16 \%$. Moreover, the $1 \%$ absolute difference in death or MI was balanced by an absolute excess of $1 \%$ in major bleeding complications associated with GpIIb-IIIa antagonists compared with controls. ${ }^{260}$

Thus, the benefit/risk profile of currently available GpIIb-IIIa antagonists is substantially uncertain for patients with ACS who are not routinely scheduled for early revascularization. In contrast, for high-risk patients undergoing PCI, intensification of antiplatelet therapy by adding an IV GpIIb-IIIa blocker is an appropriate strategy to reduce the risk of procedurerelated thrombotic complications.

Phase 2 trials in acute MI with abciximab and eptifibatide suggested potential benefits of GpIIb-IIIa blockade as an adjunct to thrombolysis. The GUSTO $\mathrm{V}$ trial compared the efficacy and safety of half-dose reteplase and full-dose abciximab vs standard-dose reteplase in 16,588 patients in the first $6 \mathrm{~h}$ of evolving ST-segment elevation MI. ${ }^{261}$ The primary end point of 30-day mortality was similar in the two treatment groups ( $5.6 \%$ vs $5.9 \%)$. Combination therapy led to a consistent reduction in secondary complications of MI, including reinfarction, which was partly counterbalanced by increased extracranial bleedings. There was no mortality benefit of combined therapy after 1 year, and thus, there appears to be little or no net benefit in combined therapy. ${ }^{261}$

The failure of several more recent randomized trials to demonstrate benefits of GpIIb-IIIa blockade among patients with ST-segment elevation MI treated with primary angioplasty and in patients treated with clopidogrel ${ }^{262,263}$ has prompted critical reevaluation of the benefits and risks of this approach in an updated meta-analysis. ${ }^{264}$ Pooled data from a meta-analysis of 16 randomized trials involving 10,085 patients undergoing primary PCI demonstrated that adjunctive GpIIb-IIIa blockade did not reduce 30-day mortality (2.8\% vs $2.9 \%, P=.75$ ) or reinfarction (1.5\% vs $1.9 \%$, $P=.22)$ and increased major bleeding $(4.1 \%$ vs $2.7 \%$, $P=.0004)$. However, meta-regression analysis demonstrated a relation between risk profile and adjunctive GpIIb-IIIa blockade and suggested a mortality benefit among those at highest risk, supporting the use of GpIIb-IIIa blockade at the time of primary PCI in selected high-risk patients with ST-segment elevation MI.

5.4.2 Cerebrovascular Disease: Despite reassuring data from a phase 2 trial of abciximab in patients with acute ischemic stroke, ${ }^{265}$ a phase 3 trial has been stopped because of safety concerns. ${ }^{266} \mathrm{~A}$ phase 2 trial of eptifibatide has also yielded promising results, ${ }^{267}$ and a further phase 2 trial with this agent is ongoing.

\subsection{CONCLUSION}

Antiplatelet therapies are effective for prevention of platelet-rich arterial thrombi that form under high-shear conditions. Antiplatelet therapies are also effective for the prevention of fibrin-rich thrombi that form under low-shear conditions, such as VTE and left atrial appendage thrombi that form in patients with atrial fibrillation, but for these indications, antiplatelet drugs are less effective than anticoagulants. The efficacy of antiplatelet drugs for thrombosis prevention is explained by their ability to block well-characterized pathways involved in platelet activation and aggregation. It is these actions that also lead to the major side effect of antiplatelet therapy, which is bleeding. The efficacy of antiplatelet therapy can be improved by increasing the intensity of therapy by using more-potent antiplatelet drugs or combinations of antiplatelet drugs but at the cost of an increase in bleeding. Under certain circumstances, efficacy can also be improved by using more rapidly acting drugs.

\section{ACKNOWLEDGMENTS}

Author contributions: As Topic Editor, Dr Eikelboom oversaw the development of this article, including any analysis and subsequent development of the information contained herein. Dr Eikelboom: contributed as Topic Editor.

Dr Hirsh: contributed as a panelist.

Dr Spencer: contributed as a panelist

Dr Baglin: contributed as a panelist.

Dr Weitz: contributed as a panelist.

Financial/nonfinancial disclosures: In summary, the authors have reported to CHEST the following conflicts of interest: Dr Eikelboom has received consulting fees and/or honoraria 
from Astra-Zeneca, Baver, Boehringer-Ingelheim, Bristol-MverSquibb, Corgenix, Daiichi-Sankyo, Eisai, Eli-Lilly, GlaxoSmithKline, Haemoscope, Johnson and Johnson, McNeil, Pfizer, Portola and Sanofi. He has received grants and/or in-kind support from Accumetrics, Astra-Zeneca, AspirinWorks, Bayer, Boehringer Ingelheim, Bristol-Myers-Squibb, Corgenix, Dade-Behring, GlaxoSmithKline, Johnson and Johnson, Portola and Sanofi. Dr Weitz has served as a consultant to Boehringer Ingelheim $\mathrm{GmbH}$, Bristol-Myers Squibb; Pfizer Inc; Daiichi-Sankyo, Inc; Bayer Healthcare Pharmaceuticals, and Johnson \& Johnson. Drs Hirsh, Spencer, and Baglin have reported that no potential conflicts of interest exist with any companies/organizations whose products or services may be discussed in this article.

Role of sponsors: The sponsors played no role in the development of these guidelines. Sponsoring organizations cannot recommend panelists or topics, nor are they allowed prepublication access to the manuscripts and recommendations. Guideline panel members, including the chair, and members of the Health \& Science Policy Committee are blinded to the funding sources. Further details on the Conflict of Interest Policy are available online at http://chestnet.org.

Endorsements: This guideline is endorsed by the American Association for Clinical Chemistry, the American College of Clinical Pharmacy, the American Society of Health-System Pharmacists, the American Society of Hematology, and the International Society of Thrombosis and Hematosis.

\section{REFERENCES}

1. Davì G, Patrono C. Platelet activation and atherothrombosis. N Engl J Med. 2007;357(24):2482-2494.

2. Kroll MH, Reséndiz JC. Mechanisms of platelet activation. In: Loscalzo J, Schafer AI, eds. Thrombosis and Hemorrhage, 3rd ed. Baltimore, MD: Williams \& Wilkins, 2002;187-205.

3. Patrono C, Coller B, FitzGerald GA, Hirsh J, Roth G. Platelet-active drugs: the relationships among dose, effectiveness, and side effects: the Seventh ACCP Conference on Antithrombotic and Thrombolytic Therapy. Chest. 2004; 126(suppl 3):234S-264S.

4. Kaushansky K. Regulation of megakaryopoiesis. In: Loscalzo J, Schafer AI, eds. Thrombosis and Hemorrhage. Baltimore, MD: Williams \& Wilkins;2002;122-139.

5. Kaushansky K. Determinants of platelet number and regulation of thrombopoiesis. Hematology (Am Soc Hematol Educ Program). 2009;2009(1):147-152.

6. Rocca B, Secchiero P, Ciabattoni G, et al. Cyclooxygenase-2 expression is induced during human megakaryopoiesis and characterizes newly formed platelets. Proc Natl Acad Sci U S A. 2002;99(11):7634-7639.

7. Lindemann S, Tolley ND, Dixon DA, et al. Activated platelets mediate inflammatory signaling by regulated interleukin 1beta synthesis. J Cell Biol. 2001;154(3):485-490.

8. Patrono C, Baigent C, Hirsh J, Roth G; American College of Chest Physicians. Antiplatelet drugs: American College of Chest Physicians Evidence-Based Clinical Practice Guidelines (8th Edition). Chest. 2008;133(6 suppl):199S-233S.

9. Patrono C, García Rodríguez LA, Landolfi R, Baigent C. Low-dose aspirin for the prevention of atherothrombosis. N Engl J Med. 2005;353(22):2373-2383.

10. Antithrombotic Trialists' Collaboration. Collaborative metaanalysis of randomised trials of antiplatelet therapy for prevention of death, myocardial infarction, and stroke in high risk patients. BMJ. 2002;324(7329):71-86.

11. Burch JW, Stanford N, Majerus PW. Inhibition of platelet prostaglandin synthetase by oral aspirin. J Clin Invest. 1978;61(2):314-319.

12. Majerus PW. Arachidonate metabolism in vascular disorders. J Clin Invest. 1983;72(5):1521-1525.
13. Roth GJ, Majerus PW. The mechanism of the effect of aspirin on human platelets. I. Acetylation of a particulate fraction protein. J Clin Invest. 1975;56(3):624-632.

14. Roth GJ, Stanford N, Majerus PW. Acetylation of prostaglandin synthase by aspirin. Proc Natl Acad Sci U S A. 1975;72(8):3073-3076.

15. Smith WL, Garavito RM, DeWitt DL. Prostaglandin endoperoxide $\mathrm{H}$ synthases (cyclooxygenases)-1 and -2. J Biol Chem. 1996;271(52):33157-33160.

16. Loll PJ, Picot D, Garavito RM. The structural basis of aspirin activity inferred from the crystal structure of inactivated prostaglandin H2 synthase. Nat Struct Biol. 1995;2(8): 637-643.

17. McAdam BF, Catella-Lawson F, Mardini IA, Kapoor S, Lawson JA, FitzGerald GA. Systemic biosynthesis of prostacyclin by cyclooxygenase (COX)-2: the human pharmacology of a selective inhibitor of COX-2. Proc Natl Acad Sci U S A. 1999;96(1):272-277.

18. Clarke RJ, Mayo G, Price P, FitzGerald GA. Suppression of thromboxane A2 but not of systemic prostacyclin by controlled-release aspirin. N Engl J Med. 1991;325(16): 1137-1141.

19. Topper JN, Cai J, Falb D, Gimbrone MA Jr. Identification of vascular endothelial genes differentially responsive to fluid mechanical stimuli: cyclooxygenase-2, manganese superoxide dismutase, and endothelial cell nitric oxide synthase are selectively up-regulated by steady laminar shear stress. Proc Natl Acad Sci U S A. 1996;93(19):10417-10422.

20. FitzGerald GA, Oates JA, Hawiger J, et al. Endogenous biosynthesis of prostacyclin and thromboxane and platelet function during chronic administration of aspirin in man. J Clin Invest. 1983;71(3):676-688.

21. Murata T, Ushikubi F, Matsuoka T, et al. Altered pain perception and inflammatory response in mice lacking prostacyclin receptor. Nature. 1997;388(6643):678-682.

22. Kearney PM, Baigent C, Godwin J, Halls H, Emberson JR, Patrono C. Do selective cyclo-oxygenase-2 inhibitors and traditional non-steroidal anti-inflammatory drugs increase the risk of atherothrombosis? Meta-analysis of randomised trials. BMJ. 2006;332(7553):1302-1308.

23. Grosser T, Fries S, FitzGerald GA. Biological basis for the cardiovascular consequences of COX-2 inhibition: therapeutic challenges and opportunities. J Clin Invest. 2006;116(1):4-15.

24. Pedersen AK, FitzGerald GA. Dose-related kinetics of aspirin. Presystemic acetylation of platelet cyclooxygenase. N Engl J Med. 1984;311(19):1206-1211.

25. Cox D, Maree AO, Dooley M, Conroy R, Byrne MF, Fitzgerald DJ. Effect of enteric coating on antiplatelet activity of low-dose aspirin in healthy volunteers. Stroke. 2006;37(8):2153-2158

26. McAdam B, Keimowitz RM, Maher M, Fitzgerald DJ. Transdermal modification of platelet function: an aspirin patch system results in marked suppression of platelet cyclooxygenase. J Pharmacol Exp Ther. 1996;277(2):559-564.

27. Thrombosis prevention trial: randomised trial of low-intensity oral anticoagulation with warfarin and low-dose aspirin in the primary prevention of ischaemic heart disease in men at increased risk. The Medical Research Council's General Practice Research Framework. Lancet. 1998;351(9098): 233-241.

28. Patrono C, Ciabattoni G, Patrignani P, et al. Clinical pharmacology of platelet cyclooxygenase inhibition. Circulation. 1985;72(6):1177-1184.

29. Burch JW, Baenziger NL, Stanford N, Majerus PW. Sensitivity of fatty acid cyclooxygenase from human aorta to acetylation by aspirin. Proc Natl Acad Sci U S A. 1978;75(10): 5181-5184. 
30. Burch JW, Majerus PW. The role of prostaglandins in platelet function. Semin Hematol. 1979;16(3):196-207.

31. Demers LM, Budin RE, Shaikh BS. The effects of aspirin on megakaryocyte prostaglandin production. Proc Soc Exp Biol Med. 1980;163(1):24-29.

32. Cerskus AL, Ali M, Davies BJ, McDonald JW. Possible significance of small numbers of functional platelets in a population of aspirin-treated platelets in vitro and in vivo. Thromb Res. 1980;18(3-4):389-397.

33. O'Brien JR. Effects of salicylates on human platelets. Lancet. 1968;1(7546):779-783.

34. Reilly IA, FitzGerald GA. Inhibition of thromboxane formation in vivo and ex vivo: implications for therapy with platelet inhibitory drugs. Blood. 1987;69(1):180-186.

35. Patrignani P, Filabozzi P, Patrono C. Selective cumulative inhibition of platelet thromboxane production by low-dose aspirin in healthy subjects. J Clin Invest. 1982;69(6):1366-1372.

36. The RISC Group. Risk of myocardial infarction and death during treatment with low dose aspirin and intravenous heparin in men with unstable coronary artery disease. Lancet. 1990;336(8719):827-830.

37. Juul-Möller S, Edvardsson N, Jahnmatz B, Rosén A, Sørensen S, Omblus R; The Swedish Angina Pectoris Aspirin Trial (SAPAT) Group. Double-blind trial of aspirin in primary prevention of myocardial infarction in patients with stable chronic angina pectoris. Lancet. 1992;340(8833): 1421-1425.

38. The SALT Collaborative Group. Swedish Aspirin LowDose Trial (SALT) of $75 \mathrm{mg}$ aspirin as secondary prophylaxis after cerebrovascular ischaemic events. Lancet. 1991; 338(8779):1345-1349.

39. Lindblad B, Persson NH, Takolander R, Bergqvist D. Does low-dose acetylsalicylic acid prevent stroke after carotid surgery? A double-blind, placebo-controlled randomized trial. Stroke. 1993;24(8):1125-1128.

40. Diener HC, Cunha L, Forbes C, Sivenius J, Smets P, Lowenthal A. European Stroke Prevention Study. 2. Dipyridamole and acetylsalicylic acid in the secondary prevention of stroke. J Neurol Sci. 1996;143(1-2):1-13.

41. Landolfi R, Marchioli R, Kutti J, etal; European Collaboration on Low-Dose Aspirin in Polycythemia Vera Investigators. Efficacy and safety of low-dose aspirin in polycythemia vera. N Engl J Med. 2004;350(2):114-124.

42. Farrell B, Godwin J, Richards S, Warlow C. The United Kingdom transient ischaemic attack (UK-TIA) aspirin trial: final results. J Neurol Neurosurg Psychiatry. 1991;54(12): 1044-1054.

43. Harris WH, Athanasoulis CA, Waltman AC, Salzman EW. High and low-dose aspirin prophylaxis against venous thromboembolic disease in total hip replacement. J Bone Joint Surg Am. 1982;64(1):63-66.

44. Harris WH, Athanasoulis CA, Waltman AC, Salzman EW. Prophylaxis of deep-vein thrombosis after total hip replacement. Dextran and external pneumatic compression compared with 1.2 or 0.3 gram of aspirin daily. J Bone Joint Surg Am. 1985;67(1):57-62.

45. McKenna R, Galante J, Bachmann F, Wallace DL, Kaushal PS, Meredith P. Prevention of venous thromboembolism after total knee replacement by high-dose aspirin or intermittent calf and thigh compression. BMJ. 1980;280(6213):514-517.

46. Taylor DW, Barnett HJ, Haynes RB, et al. Low-dose and high-dose acetylsalicylic acid for patients undergoing carotid endarterectomy: a randomised controlled trial. ASA and Carotid Endarterectomy (ACE) Trial Collaborators. Lancet. 1999;353(9171):2179-2184.

47. The Dutch TIA Trial Study Group. A comparison of two doses of aspirin (30 mg vs. $283 \mathrm{mg}$ a day) in patients after a transient ischemic attack or minor ischemic stroke. $N$ Engl J Med. 1991;325(18):1261-1266.

48. Mehta SR, Bassand JP, Chrolavicius S, et al; CURRENTOASIS 7 Investigators. Dose comparisons of clopidogrel and aspirin in acute coronary syndromes [published correction appears in N Engl J Med. 2010;363(16):1585]. N Engl J Med. 2010;363(10):930-942.

49. Lewis HD Jr, Davis JW, Archibald DG, et al. Protective effects of aspirin against acute myocardial infarction and death in men with unstable angina. Results of a Veterans Administration Cooperative Study. N Engl J Med. 1983; 309(7):396-403.

50. Théroux P, Ouimet H, McCans J, et al. Aspirin, heparin, or both to treat acute unstable angina. N Engl J Med. 1988; 319(17):1105-1111.

51. Cairns JA, Gent M, Singer J, et al. Aspirin, sulfinpyrazone, or both in unstable angina. Results of a Canadian multicenter trial. N Engl J Med. 1985;313(22):1369-1375.

52. Lorenz RL, Schacky CV, Weber M, et al. Improved aortocoronary bypass patency by low-dose aspirin (100 mg daily). Effects on platelet aggregation and thromboxane formation. Lancet. 1984;1(8389):1261-1264.

53. Goldman S, Copeland J, Moritz T, et al. Improvement in early saphenous vein graft patency after coronary artery bypass surgery with antiplatelet therapy: results of a Veterans Administration Cooperative Study. Circulation. 1988;77(6): 1324-1332.

54. Brown BG, Cukingnan RA, DeRouen T, et al. Improved graft patency in patients treated with platelet-inhibiting therapy after coronary bypass surgery. Circulation. 1985; 72(1):138-146.

55. Turpie AG, Gent M, Laupacis A, et al. A comparison of aspirin with placebo in patients treated with warfarin after heart-valve replacement. $N$ Engl J Med. 1993;329(8): 524-529.

56. Altman R, Boullon F, Rouvier J, Raca R, de la Fuente L, Favaloro R. Aspirin and prophylaxis of thromboembolic complications in patients with substitute heart valves. J Thorac Cardiovasc Surg. 1976;72(1):127-129.

57. Chesebro JH, Fuster V, Elveback LR, et al. Trial of combined warfarin plus dipyridamole or aspirin therapy in prosthetic heart valve replacement: danger of aspirin compared with dipyridamole. Am J Cardiol. 1983;51(9):1537-1541.

58. Dale J, Myhre E, Storstein O, Stormorken H, Efskind L. Prevention of arterial thromboembolism with acetylsalicylic acid. A controlled clinical study in patients with aortic ball valves. Am Heart J. 1977;94(1):101-111.

59. Harter HR, Burch JW, Majerus PW, et al. Prevention of thrombosis in patients on hemodialysis by low-dose aspirin. N Engl J Med. 1979;301(11):577-579.

60. ISIS-2 (Second International Study of Infarct Survival) Collaborative Group. Randomized trial of intravenous streptokinase, oral aspirin, both, or neither among 17,187 cases of suspected acute myocardial infarction: ISIS-2.. J Am Coll Cardiol. 1988;12(6)(suppl A):A3-A13.

61. Barnett HJ, Kaste M, Meldrum H, Eliasziw M. Aspirin dose in stroke prevention: beautiful hypotheses slain by ugly facts. Stroke. 1996;27(4):588-592.

62. Bousser MG, Eschwege E, Haguenau M, et al. "AICLA" controlled trial of aspirin and dipyridamole in the secondary prevention of athero-thrombotic cerebral ischemia. Stroke. 1983;14(1):5-14.

63. Fields WS, Lemak NA, Frankowski RF, Hardy RJ. Controlled trial of aspirin in cerebral ischemia. Stroke. 1977; 8(3):301-314.

64. Chen Z-M; CAST (Chinese Acute Stroke Trial) Collaborative Group. CAST: randomised placebo-controlled trial of early 
aspirin use in 20,000 patients with acute ischaemic stroke. Lancet. 1997;349(9066):1641-1649.

65. International Stroke Trial Collaborative Group. The International Stroke Trial (IST): a randomised trial of aspirin, subcutaneous heparin, both, or neither among 19435 patients with acute ischaemic stroke. Lancet. 1997;349(9065): 1569-1581.

66. Tartaglia AP, Goldberg JD, Berk PD, Wasserman LR. Adverse effects of antiaggregating platelet therapy in the treatment of polycythemia vera. Semin Hematol. 1986;23(3): 172-176.

67. Peters RJ, Mehta SR, Fox KA, et al; Clopidogrel in Unstable angina to prevent Recurrent Events (CURE) Trial Investigators. Effects of aspirin dose when used alone or in combination with clopidogrel in patients with acute coronary syndromes: observations from the Clopidogrel in Unstable angina to prevent Recurrent Events (CURE) study. Circulation. 2003;108(14):1682-1687.

68. Buchanan MR, Rischke JA, Hirsh J. Aspirin inhibits platelet function independent of the acetylation of cyclo-oxygenase. Thromb Res. 1982;25(5):363-373.

69. Gaspari F, Viganò G, Orisio S, Bonati M, Livio M, Remuzzi G. Aspirin prolongs bleeding time in uremia by a mechanism distinct from platelet cyclooxygenase inhibition. J Clin Invest. 1987;79(6):1788-1797.

70. Hanson SR, Harker LA, Bjornsson TD. Effects of plateletmodifying drugs on arterial thromboembolism in baboons. Aspirin potentiates the antithrombotic actions of dipyridamole and sulfinpyrazone by mechanism(s) independent of platelet cyclooxygenase inhibition. J Clin Invest. 1985; 75(5):1591-1599.

71. Harker LA, Fuster V. Pharmacology of platelet inhibitors. J Am Coll Cardiol. 1986;8(6)(Suppl B):21B-32B.

72. Ratnatunga CP, Edmondson SF, Rees GM, Kovacs IB. High-dose aspirin inhibits shear-induced platelet reaction involving thrombin generation. Circulation. 1992;85(3): 1077-1082.

73. Bjornsson TD, Schneider DE, Hecht AR. Effects of $\mathrm{N}$-deacetylation and N-desulfation of heparin on its anticoagulant activity and in vivo disposition. J Pharmacol Exp Ther. 1988;245(3):804-808.

74. Green D, Davies RO, Holmes GI, et al. Fibrinolytic activity after administration of diflunisal and aspirin. A double-blind, randomized, placebo-controlled clinical trial. Haemostasis. 1983;13(6):394-398.

75. Moroz LA. Increased blood fibrinolytic activity after aspirin ingestion. N Engl J Med. 1977;296(10):525-529.

76. Kessels H, Béguin S, Andree H, Hemker HC. Measurement of thrombin generation in whole blood-the effect of heparin and aspirin. Thromb Haemost. 1994;72(1): $78-83$.

77. Loew D, Vinazzer H. Dose-dependent influence of acetylsalicyclic acid on platelet functions and plasmatic coagulation factors. Haemostasis. 1976;5(4):239-249.

78. Quick AJ, Clesceri L. Influence of acetylsalicylic acid and salicylaide on the coagulation of blood. J Pharmacol Exp Ther. 1960;128:95-98.

79. Szczeklik A, Krzanowski M, Góra P, Radwan J. Antiplatelet drugs and generation of thrombin in clotting blood. Blood. 1992;80(8):2006-2011.

80. Gurbel PA, Bliden KP, DiChiara J, et al. Evaluation of dose-related effects of aspirin on platelet function: results from the Aspirin-Induced Platelet Effect (ASPECT) study. Circulation. 2007;115(25):3156-3164.

81. Capone ML, Sciulli MG, TacconelliS, etal.Pharmacodynamic interaction of naproxen with low-dose aspirin in healthy subjects. J Am Coll Cardiol. 2005;45(8):1295-1301.
82. Catella-Lawson F, Reilly MP, Kapoor SC, et al. Cyclooxygenase inhibitors and the antiplatelet effects of aspirin. N Engl J Med. 2001;345(25):1809-1817.

83. Renda G, Tacconelli S, Capone ML, et al. Celecoxib, ibuprofen, and the antiplatelet effect of aspirin in patients with osteoarthritis and ischemic heart disease. Clin Pharmacol Ther. 2006;80(3):264-274.

84. FitzGerald GA, Patrono C. The coxibs, selective inhibitors of cyclooxygenase-2. N Engl J Med. 2001;345(6):433-442.

85. US Food and Drug Administration. Information for Healthcare Professionals: Concomitant Use of Ibuprofen and Aspirin. Rockville, MD: FDA Medwatch; 2010.

86. The Canadian Cooperative Study Group. A randomized trial of aspirin and sulfinpyrazone in threatened stroke. $N$ Engl J Med. 1978;299(2):53-59.

87. Baigent C, Blackwell L, Collins R, et al; Antithrombotic Trialists' (ATT) Collaboration. Aspirin in the primary and secondary prevention of vascular disease: collaborative metaanalysis of individual participant data from randomised trials. Lancet. 2009;373(9678):1849-1860.

88. de Gaetano G; Collaborative Group of the Primary Prevention Project. Low-dose aspirin and vitamin E in people at cardiovascular risk: a randomised trial in general practice. Lancet. 2001;357(9250):89-95.

89. Hansson L, Zanchetti A, Carruthers SG, et al; HOT Study Group. Effects of intensive blood-pressure lowering and low-dose aspirin in patients with hypertension: principal results of the Hypertension Optimal Treatment (HOT) randomised trial. Lancet. 1998;351(9118):1755-1762.

90. Peto R, Gray R, Collins R, et al. Randomised trial of prophylactic daily aspirin in British male doctors. Br Med J (Clin Res Ed). 1988;296(6618):313-316.

91. Ridker PM, Cook NR, Lee IM, et al. A randomized trial of low-dose aspirin in the primary prevention of cardiovascular disease in women. N Engl J Med. 2005;352(13):1293-1304.

92. Steering Committee of the Physicians' Health Study Research Group. Final report on the aspirin component of the ongoing Physicians' Health Study. N Engl J Med. 1989;321(3): 129-135.

93. Ogawa $\mathrm{H}$, Nakayama $\mathrm{M}$, Morimoto $\mathrm{T}$, et al; Japanese Primary Prevention of Atherosclerosis With Aspirin for Diabetes (JPAD) Trial Investigators. Low-dose aspirin for primary prevention of atherosclerotic events in patients with type 2 diabetes: a randomized controlled trial. JAMA. 2008;300(18):2134-2141.

94. Belch J, MacCuish A, Campbell I, et al. The prevention of progression of arterial disease and diabetes (POPADAD) trial: factorial randomised placebo controlled trial of aspirin and antioxidants in patients with diabetes and asymptomatic peripheral arterial disease. BMJ. 2008;337:a1840

95. Fowkes FG, Price JF, Stewart MC, et al; Aspirin for Asymptomatic Atherosclerosis Trialists. Aspirin for prevention of cardiovascular events in a general population screened for a low ankle brachial index: a randomized controlled trial. JAMA. 2010;303(9):841-848.

96. Raju N, Sobieraj-Teague M, Hirsh J, O’Donnell M, Eikelboom JW. Effect of aspirin on mortality in primary prevention of cardiovascular disease. Am J Med, 2011;124(7):621-629.

97. Ikeda Y. Japanese Primary Prevention Project with Aspirin. Bethesda, MD: National Institutes of Health; 2005.

98. Nelson M, Reid C, Beilin L, et al; Aspirin in Reducing Events in the Elderly (ASPREE) Study Group. Rationale for a trial of low-dose aspirin for the primary prevention of major adverse cardiovascular events and vascular dementia in the elderly: Aspirin in Reducing Events in the Elderly (ASPREE). Drugs Aging. 2003;20(12):897-903. 
99. De Berardis G, Sacco M, Evangelista V, et al; ACCEPT-D Study Group. Aspirin and Simvastatin Combination for Cardiovascular Events Prevention Trial in Diabetes (ACCEPT-D): design of a randomized study of the efficacy of low-dose aspirin in the prevention of cardiovascular events in subjects with diabetes mellitus treated with statins. Trials. 2007;8:21.

100. Vandvik PO, Lincoff AM, Gore JM, et al. Primary and secondary prevention of cardiovascular disease: antithrombotic therapy and prevention of thrombosis, 9th ed: American College of Chest Physicians evidence-based clinical practice guidelines. Chest. 2012:141(2)(suppl):e637S-e668S

101. Hart RG, Pearce LA, Aguilar MI. Meta-analysis: antithrombotic therapy to prevent stroke in patients who have nonvalvular atrial fibrillation. Ann Intern Med. 2007;146(12): 857-867.

102. Connolly SJ, Ezekowitz MD, Yusuf S, Reilly PA, Wallentin L; Randomized Evaluation of Long-Term Anticoagulation Therapy Investigators. Newly identified events in the RE-LY trial. N Engl J Med. 2010;363(19):1875-1876.

103. Connolly SJ, Eikelboom J, Joyner C, et al; AVERROES Steering Committee and Investigators. Apixaban in patients with atrial fibrillation. N Engl J Med. 2011;364(9):806-817.

104. Hart RG, Pearce LA, Aguilar MI. Adjusted-dose warfarin versus aspirin for preventing stroke in patients with atrial fibrillation. Ann Intern Med. 2007;147(8):590-592.

105. Connolly S, Pogue J, Hart R, et al; ACTIVE Writing Group of the ACTIVE Investigators. Clopidogrel plus aspirin versus oral anticoagulation for atrial fibrillation in the Atrial fibrillation Clopidogrel Trial with Irbesartan for prevention of Vascular Events (ACTIVE W): a randomised controlled trial. Lancet. 2006;367(9526):1903-1912.

106. Connolly SJ, Pogue J, Hart RG, et al; ACTIVE Investigators. Effect of clopidogrel added to aspirin in patients with atrial fibrillation. N Engl J Med. 2009;360(20):2066-2078.

107. You JJ, Singer DE, Howard PA, et al. Antithrombotic therapy for atrial fibrillation: antithrombotic therapy and prevention of thrombosis, 9th ed: American College of Chest Physicians evidence-based clinical practice guidelines. Chest. 2012;141(2)(suppl):e531S-e575S.

108. Pulmonary Embolism Prevention (PEP) trial Collaborative Group. Prevention of pulmonary embolism and deep vein thrombosis with low dose aspirin: Pulmonary Embolism Prevention (PEP) trial. Lancet. 2000;355(9212):1295-1302.

109. Antiplatelet Trialists' Collaboration. Collaborative overview of randomised trials of antiplatelet therapy-I: Prevention of death, myocardial infarction, and stroke by prolonged antiplatelet therapy in various categories of patients. BMJ. 1994;308(6921):81-106.

110. Sandercock PA, Counsell C, Kamal AK. Anticoagulants for acute ischaemic stroke. Cochrane Database Syst Rev. 2008; (4):CD000024.

111. Karthikeyan G, Eikelboom JW, Turpie AG, Hirsh J. Does acetyl salicylic acid (ASA) have a role in the prevention of venous thromboembolism? Br J Haematol. 2009;146(2): 142-149.

112. Falck-Ytter Y, Francis CW, Johanson NA, et al. Prevention of VTE in orthopedic surgery patients: antithrombotic therapy and prevention of thrombosis, 9th ed: American College of Chest Physicians evidence-based clinical practice guidelines. Chest. 2012;141(2)(suppl):e278S-e325S.

113. Imperiale TF, Petrulis AS. A meta-analysis of low-dose aspirin for the prevention of pregnancy-induced hypertensive disease. JAMA. 1991;266(2):260-264.

114. Uzan S, Beaufils M, Breart G, Bazin B, Capitant C, Paris J. Prevention of fetal growth retardation with low-dose aspirin: findings of the EPREDA trial. Lancet. 1991;337(8755): $1427-1431$.
115. Caritis S, Sibai B, Hauth J, et al; National Institute of Child Health and Human Development Network of MaternalFetal Medicine Units. Low-dose aspirin to prevent preeclampsia in women at high risk. N Engl J Med. 1998;338(11): 701-705.

116. CLASP (Collaborative Low-dose Aspirin Study in Pregnancy) Collaborative Group. CLASP: a randomised trial of low-dose aspirin for the prevention and treatment of pre-eclampsia among 9364 pregnant women. Lancet. 1994;343(8898):619-629.

117. ECPPA. ECPPA: randomised trial of low dose aspirin for the prevention of maternal and fetal complications in high risk pregnant women. ECPPA (Estudo Colaborativo para Prevenção da Pré-eclampsia com Aspirina) Collaborative Group. Br J Obstet Gynaecol. 1996;103(1):39-47.

118. Golding J; The Jamaica Low Dose Aspirin Study Group. A randomised trial of low dose aspirin for primiparae in pregnancy. Br J Obstet Gynaecol. 1998;105(3):293-299.

119. Low-dose aspirin in prevention and treatment of intrauterine growth retardation and pregnancy-induced hypertension. Italian study of aspirin in pregnancy. Lancet. 1993;341(8842): 396-400.

120. Rotchell YE, Cruickshank JK, Gay MP, et al. Barbados Low Dose Aspirin Study in Pregnancy (BLASP): a randomised trial for the prevention of pre-eclampsia and its complications. Br J Obstet Gynaecol. 1998;105(3):286-292.

121. Sibai BM, Caritis SN, Thom E, et al; The National Institute of Child Health and Human Development Network of Maternal-Fetal Medicine Units. Prevention of preeclampsia with low-dose aspirin in healthy, nulliparous pregnant women. N Engl J Med. 1993;329(17):1213-1218.

122. Duley L, Henderson-Smart DJ, Meher S, King JF. Antiplatelet agents for preventing pre-eclampsia and its complications. Cochrane Database Syst Rev. 2007;(2):CD004659.

123. Askie LM, Duley L, Henderson-Smart DJ, Stewart LA; PARIS Collaborative Group. Antiplatelet agents for prevention of pre-eclampsia: a meta-analysis of individual patient data. Lancet. 2007;369(9575):1791-1798.

124. Bates SM, Greer IA, Middeldorp S, Veenstra D, Prabulos A-M, Vandvik PO. VTE, thrombophilia, antithrombotic therapy, and pregnancy: antithrombotic therapy and prevention of thrombosis, 9th ed: American College of Chest Physicians evidence-based clinical practice guidelines. Chest. 2012; 141(2)(suppl):e691S-e736S

125. Rothwell PM, Fowkes FG, Belch JF, Ogawa H, Warlow CP, Meade TW. Effect of daily aspirin on long-term risk of death due to cancer: analysis of individual patient data from randomised trials. Lancet. 2011;377(9759):31-41.

126. Rothwell PM, Wilson M, Elwin CE, et al. Long-term effect of aspirin on colorectal cancer incidence and mortality: 20-year follow-up of five randomised trials. Lancet. 2010;376(9754):1741-1750.

127. Roderick PJ, Wilkes HC, Meade TW. The gastrointestinal toxicity of aspirin: an overview of randomised controlled trials. Br J Clin Pharmacol. 1993;35(3):219-226.

128. García Rodríguez LA, Cattaruzzi C, Troncon MG, Agostinis L. Risk of hospitalization for upper gastrointestinal tract bleeding associated with ketorolac, other nonsteroidal anti-inflammatory drugs, calcium antagonists, and other antihypertensive drugs. Arch Intern Med. 1998;158(1):33-39.

129. Weil J, Colin-Jones D, Langman M, et al. Prophylactic aspirin and risk of peptic ulcer bleeding. BMJ. 1995;310(6983): 827-830.

130. García Rodríguez LA, Hernández-Díaz S, de Abajo FJ. Association between aspirin and upper gastrointestinal complications: systematic review of epidemiologic studies. $\mathrm{Br} J$ Clin Pharmacol. 2001;52(5):563-571. 
131. Lanas A, Perez-Aisa MA, Feu F, et al; Investigators of the Asociación Española de Gastroenterología (AEG). A nationwide study of mortality associated with hospital admission due to severe gastrointestinal events and those associated with nonsteroidal antiinflammatory drug use. Am J Gastroenterol. 2005;100(8):1685-1693.

132. Wolfe MM, Lichtenstein DR, Singh G. Gastrointestinal toxicity of nonsteroidal antiinflammatory drugs. $N$ Engl J Med. 1999;340(24):1888-1899.

133. Kelly JP, Kaufman DW, Jurgelon JM, Sheehan J, Koff RS, Shapiro S. Risk of aspirin-associated major upper-gastrointestinal bleeding with enteric-coated or buffered product. Lancet. 1996;348(9039):1413-1416.

134. de Abajo FJ, García Rodríguez LA. Risk of upper gastrointestinal bleeding and perforation associated with low-dose aspirin as plain and enteric-coated formulations. BMC Clin Pharmacol. 2001;1:1.

135. Yeomans ND, Tulassay Z, Juhász L, et al. A comparison of omeprazole with ranitidine for ulcers associated with nonsteroidal antiinflammatory drugs. Acid Suppression Trial: Ranitidine versus Omeprazole for NSAID-associated Ulcer Treatment (ASTRONAUT) Study Group. $N$ Engl J Med. 1998;338(11):719-726.

136. Hawkey CJ, Karrasch JA, Szczepañski L, et al. Omeprazole compared with misoprostol for ulcers associated with nonsteroidal antiinflammatory drugs. Omeprazole versus Misoprostol for NSAID-induced Ulcer Management (OMNIUM) Study Group. N Engl J Med. 1998;338(11):727-734.

137. Chan FK, Chung SC, Suen BY, et al. Preventing recurrent upper gastrointestinal bleeding in patients with Helicobacter pylori infection who are taking low-dose aspirin or naproxen. N Engl J Med. 2001;344(13):967-973.

138. Chan FK, Ching JY, Hung LC, et al. Clopidogrel versus aspirin and esomeprazole to prevent recurrent ulcer bleeding. $N$ Engl J Med. 2005;352(3):238-244.

139. Lai KC, Chu KM, Hui WM, et al. Esomeprazole with aspirin versus clopidogrel for prevention of recurrent gastrointestinal ulcer complications. Clin Gastroenterol Hepatol. 2006;4(7):860-865.

140. Bhatt DL, Scheiman J, Abraham NS, et al; American College of Cardiology Foundation Task Force on Clinical Expert Consensus Documents. ACCF/ACG/AHA 2008 expert consensus document on reducing the gastrointestinal risks of antiplatelet therapy and NSAID use: a report of the American College of Cardiology Foundation Task Force on Clinical Expert Consensus Documents. Circulation. 2008;118(18):1894-1909.

141. Iso H, Hennekens CH, Stampfer MJ, et al. Prospective study of aspirin use and risk of stroke in women. Stroke. 1999;30(9):1764-1771.

142. Mené P, Pugliese F, Patrono C. The effects of nonsteroidal anti-inflammatory drugs on human hypertensive vascular disease. Semin Nephrol. 1995; 15(3):244-252.

143. Pierucci A, Simonetti BM, Pecci G, et al. Improvement of renal function with selective thromboxane antagonism in lupus nephritis. N Engl J Med. 1989;320(7):421-425.

144. Al-Khadra AS, Salem DN, Rand WM, Udelson JE, Smith JJ, Konstam MA. Antiplatelet agents and survival: a cohort analysis from the Studies of Left Ventricular Dysfunction (SOLVD) trial. J Am Coll Cardiol. 1998;31(2):419-425.

145. Latini R, Tognoni G, Maggioni AP, et al; Angiotensinconverting Enzyme Inhibitor Myocardial Infarction Collaborative Group. Clinical effects of early angiotensin-converting enzyme inhibitor treatment for acute myocardial infarction are similar in the presence and absence of aspirin: systematic overview of individual data from 96,712 randomized patients. J Am Coll Cardiol. 2000;35(7):1801-1807.
146. Zanchetti A, Hansson L, Leonetti G, et al. Low-dose aspirin does not interfere with the blood pressure-lowering effects of antihypertensive therapy. J Hypertens. 2002;20(5): 1015-1022.

147. Teo KK, Yusuf S, Pfeffer M, et al; ACE Inhibitors Collaborative Group. Effects of long-term treatment with angiotensin-converting-enzyme inhibitors in the presence or absence of aspirin: a systematic review. Lancet. 2002; 360(9339):1037-1043.

148. Born G, Patrono C. Antiplatelet drugs. Br J Pharmacol. 2006;147(suppl 1):S241-S251.

149. Weyrich AS, Denis MM, Kuhlmann-Eyre JR, et al. Dipyridamole selectively inhibits inflammatory gene expression in platelet-monocyte aggregates. Circulation. 2005; 111(5):633-642.

150. Müller TH, Su CA, Weisenberger H, Brickl R, Nehmiz G, Eisert WG. Dipyridamole alone or combined with low-dose acetylsalicylic acid inhibits platelet aggregation in human whole blood ex vivo. Br J Clin Pharmacol. 1990;30(2): 179-186.

151. De Schryver EL, Algra A, van Gijn J. Dipyridamole for preventing stroke and other vascular events in patients with vascular disease. Cochrane Database Syst Rev. 2007;(3): CD001820.

152. Halkes PH, van Gijn J, Kappelle LJ, Koudstaal PJ, Algra A; ESPRIT Study Group. Aspirin plus dipyridamole versus aspirin alone after cerebral ischaemia of arterial origin (ESPRIT): randomised controlled trial. Lancet. 2006; 367(9523):1665-1673.

153. Sacco RL, Diener HC, Yusuf S, et al; PRoFESS Study Group. Aspirin and extended-release dipyridamole versus clopidogrel for recurrent stroke. N Engl J Med. 2008;359(12): 1238-1251.

154. Verro P, Gorelick PB, Nguyen D. Aspirin plus dipyridamole versus aspirin for prevention of vascular events after stroke or TIA: a meta-analysis. Stroke. 2008;39(4):1358-1363.

155. De Schryver EL, Algra A, van Gijn J. Dipyridamole for preventing stroke and other vascular events in patients with vascular disease. an Update. Stroke. 2008;39:1297-1398.

156. Thompson PD, Zimet R, Forbes WP, Zhang P. Meta-analysis of results from eight randomized, placebo-controlled trials on the effect of cilostazol on patients with intermittent claudication. Am J Cardiol. 2002;90(12):1314-1319.

157. Uchiyama S, Demaerschalk BM, Goto S, et al. Stroke prevention by cilostazol in patients with atherothrombosis: meta-analysis of placebo-controlled randomized trials. J Stroke Cerebrovasc Dis. 2009;18(6):482-490.

158. Biondi-Zoccai GG, Lotrionte M, Anselmino M, et al. Systematic review and meta-analysis of randomized clinical trials appraising the impact of cilostazol after percutaneous coronary intervention. Am Heart J. 2008;155(6):1081-1089.

159. Shinohara Y, Katayama Y, Uchiyama S, et al; CSPS 2 group. Cilostazol for prevention of secondary stroke (CSPS 2): an aspirin-controlled, double-blind, randomised non-inferiority trial. Lancet Neurol. 2010;9(10):959-968.

160. Savi P, Herbert JM. Clopidogrel and ticlopidine: P2Y12 adenosine diphosphate-receptor antagonists for the prevention of atherothrombosis. Semin Thromb Hemost. 2005;31(2): 174-183.

161. Armstrong PC, Dhanji AR, Tucker AT, Mitchell JA, Warner TD. Reduction of platelet thromboxane A2 production ex vivo and in vivo by clopidogrel therapy. J Thromb Haemost. 2010;8(3):613-615.

162. Armstrong PC, Leadbeater PD, Chan MV, et al. In the presence of strong P2Y12 receptor blockade, aspirin provides little additional inhibition of platelet aggregation. J Thromb Haemost. 2010;9(3):552-561. 
163. Gent M, Blakely JA, Easton JD, et al. The Canadian American Ticlopidine Study (CATS) in thromboembolic stroke. Lancet. 1989;1(8649):1215-1220.

164. Hass WK, Easton JD, Adams HP Jr, et al; Ticlopidine Aspirin Stroke Study Group. A randomized trial comparing ticlopidine hydrochloride with aspirin for the prevention of stroke in high-risk patients. N Engl J Med. 1989;321(8): 501-507.

165. Balsano F, Rizzon P, Violi F, et al. Antiplatelet treatment with ticlopidine in unstable angina. A controlled multicenter clinical trial. The Studio della Ticlopidina nell'Angina Instabile Group. Circulation. 1990;82(1):17-26.

166. Scrutinio D, Cimminiello C, Marubini E, Pitzalis MV, Di Biase M, Rizzon P. Ticlopidine versus aspirin after myocardial infarction (STAMI) trial. J Am Coll Cardiol. 2001;37(5):1259-1265.

167. Arcan JC, Blanchard J, Boissel JP, Destors JM, Panak E. Multicenter double-blind study of ticlopidine in the treatment of intermittent claudication and the prevention of its complications. Angiology. 1988;39(9):802-811.

168. Balsano F, Coccheri S, Libretti A, et al. Ticlopidine in the treatment of intermittent claudication: a 21-month doubleblind trial. J Lab Clin Med. 1989;114(1):84-91.

169. Janzon L, Bergqvist D, Boberg J, et al. Prevention of myocardial infarction and stroke in patients with intermittent claudication; effects of ticlopidine. Results from STIMS, the Swedish Ticlopidine Multicentre Study. J Intern Med. 1990;227(5):301-308.

170. Limet R, David JL, Magotteaux P, Larock MP, Rigo P. Prevention of aorta-coronary bypass graft occlusion. Beneficial effect of ticlopidine on early and late patency rates of venous coronary bypass grafts: a double-blind study. J Thorac Cardiovasc Surg. 1987;94(5):773-783.

171. FitzGerald GA. Ticlopidine in unstable angina. A more expensive aspirin? Circulation. 1990;82(1):296-298.

172. Yeh SP, Hsueh EJ, Wu H, Wang YC. Ticlopidine-associated aplastic anemia. A case report and review of literature. Ann Hematol. 1998;76(2):87-90.

173. Bennett CL, Davidson CJ, Raisch DW, Weinberg PD, Bennett RH, Feldman MD. Thrombotic thrombocytopenic purpura associated with ticlopidine in the setting of coronary artery stents and stroke prevention. Arch Intern Med. 1999; 159(21):2524-2528.

174. Leon MB, Baim DS, Popma JJ, et al; Stent Anticoagulation Restenosis Study Investigators. A clinical trial comparing three antithrombotic-drug regimens after coronary-artery stenting. N Engl J Med. 1998;339(23):1665-1671.

175. More RS, Chauhan A. Antiplatelet rather than anticoagulant therapy with coronary stenting. Lancet. 1997;349(9046): 146-147.

176. Bhatt DL, Bertrand ME, Berger PB, et al. Meta-analysis of randomized and registry comparisons of ticlopidine with clopidogrel after stenting. J Am Coll Cardiol. 2002;39(1):9-14.

177. Steinhubl SR, Tan WA, Foody JM, Topol EJ. Incidence and clinical course of thrombotic thrombocytopenic purpura due to ticlopidine following coronary stenting. EPISTENT Investigators. Evaluation of Platelet IIb/IIIa Inhibitor for Stenting. JAMA. 1999;281(9):806-810.

178. Savi P, Pereillo JM, Uzabiaga MF, et al. Identification and biological activity of the active metabolite of clopidogrel. Thromb Haemost. 2000;84(5):891-896.

179. Pereillo JM, Maftouh M, Andrieu A, et al. Structure and stereochemistry of the active metabolite of clopidogrel. Drug Metab Dispos. 2002;30(11):1288-1295.

180. Herbert JM, Frehel D, Vallee E, et al. Clopidogrel, a novel antiplatelet and antithrombotic agent. Cardiovasc Drug Rev. 1993;11(2):180-198.
181. Savcic M, Hauert J, Bachmann F, Wyld PJ, Geudelin B, Cariou R. Clopidogrel loading dose regimens: kinetic profile of pharmacodynamic response in healthy subjects. Semin Thromb Hemost. 1999;25(suppl 2):15-19.

182. Hochholzer W, Trenk D, Frundi D, et al. Time dependence of platelet inhibition after a 600-mg loading dose of clopidogrel in a large, unselected cohort of candidates for percutaneous coronary intervention. Circulation. 2005; $111(20): 2560-2564$

183. von Beckerath N, Taubert D, Pogatsa-Murray G, Schömig E, Kastrati A, Schömig A. Absorption, metabolization, and antiplatelet effects of 300-, 600-, and 900-mg loading doses of clopidogrel: results of the ISAR-CHOICE (Intracoronary Stenting and Antithrombotic Regimen: Choose Between 3 High Oral Doses for Immediate Clopidogrel Effect) Trial. Circulation. 2005;112(19):2946-2950.

184. Cuisset T, Frere C, Quilici J, et al. Benefit of a 600-mg loading dose of clopidogrel on platelet reactivity and clinical outcomes in patients with non-ST-segment elevation acute coronary syndrome undergoing coronary stenting. J Am Coll Cardiol. 2006;48(7):1339-1345.

185. Montalescot G, Sideris G, Meuleman C, et al; ALBION Trial Investigators. A randomized comparison of high clopidogrel loading doses in patients with non-ST-segment elevation acute coronary syndromes: the ALBION (Assessment of the Best Loading Dose of Clopidogrel to Blunt Platelet Activation, Inflammation and Ongoing Necrosis) trial. J Am Coll Cardiol. 2006;48(5):931-938.

186. Bonello L, Tantry US, Marcucci R, et al; Working Group on High On-Treatment Platelet Reactivity. Consensus and future directions on the definition of high on-treatment platelet reactivity to adenosine diphosphate. J Am Coll Cardiol. 2010;56(12):919-933.

187. Zahno A, Brecht K, Bodmer M, Bur D, Tsakiris DA, Krähenbühl S. Effects of drug interactions on biotransformation and antiplatelet effect of clopidogrel in vitro. $\mathrm{Br} J$ Pharmacol. 2010;161(2):393-404.

188. Angiolillo DJ, Gibson CM, Cheng S, et al. Differential effects of omeprazole and pantoprazole on the pharmacodynamics and pharmacokinetics of clopidogrel in healthy subjects: randomized, placebo-controlled, crossover comparison studies. Clin Pharmacol Ther. 2011;89(1):65-74.

189. Wienbergen H, Gitt AK, Schiele R, et al; MITRA PLUS Study Group. Comparison of clinical benefits of clopidogrel therapy in patients with acute coronary syndromes taking atorvastatin versus other statin therapies. Am J Cardiol. 2003;92(3):285-288.

190. Siller-Matula JM, Jilma B, Schrör K, Christ G, Huber K. Effect of proton pump inhibitors on clinical outcome in patients treated with clopidogrel: a systematic review and meta-analysis. J Thromb Haemost. 2010;8(12):2624-2641.

191. Bhatt DL, Cryer BL, Contant CF, et al; COGENT Investigators. Clopidogrel with or without omeprazole in coronary artery disease. N Engl J Med. 2010;363(20): 1909-1917.

192. Mukherjee D, Kline-Rogers E, Fang J, Munir K, Eagle KA. Lack of clopidogrel-CYP3A4 statin interaction in patients with acute coronary syndrome. Heart. 2005;91(1):23-26.

193. Saw J, Steinhubl SR, Berger PB, et al; Clopidogrel for the Reduction of Events During Observation Investigators. Lack of adverse clopidogrel-atorvastatin clinical interaction from secondary analysis of a randomized, placebocontrolled clopidogrel trial. Circulation. 2003;108(8): 921-924.

194. Lim MJ, Spencer FA, Gore JM, et al; GRACE Investigators. Impact of combined pharmacologic treatment with clopidogrel and a statin on outcomes of patients with non-ST-segment 
elevation acute coronary syndromes: perspectives from a large multinational registry. Eur Heart J. 2005;26(11): 1063-1069.

195. Mega JL, Simon T, Collet JP, et al. Reduced-function CYP2C19 genotype and risk of adverse clinical outcomes among patients treated with clopidogrel predominantly for PCI: a meta-analysis. JAMA. 2010;304(16):1821-1830.

196. Wallentin L, James S, Storey RF, et al; PLATO investigators. Effect of CYP2C19 and ABCB1 single nucleotide polymorphisms on outcomes of treatment with ticagrelor versus clopidogrel for acute coronary syndromes: a genetic substudy of the PLATO trial. Lancet. 2010;376(9749):1320-1328.

197. Paré G, Mehta SR, Yusuf S, et al. Effects of CYP2C19 genotype on outcomes of clopidogrel treatment. $N$ Engl J Med. 2010;363(18):1704-1714.

198. Fuster V, Sweeny JM. Clopidogrel and the reduced-function CYP2C19 genetic variant: a limited piece of the overall therapeutic puzzle. JAMA. 2010;304(16):1839-1840.

199. Price MJ, Berger PB, Teirstein PS, et al; GRAVITAS Investigators. Standard- vs high-dose clopidogrel based on platelet function testing after percutaneous coronary intervention: the GRAVITAS randomized trial [published correction appears in JAMA. 2011;305(21);2174]. JAMA. 2011;305(11):1097-1105.

200. Sobieraj-Teague M, Eikelboom JW. Point-of-care testing for assessment of adequacy of oral antiplatelet therapy in patients with cardiovascular disease. Future Cardiol. 2010; 6(3):289-299.

201. CAPRIE Steering Committee. A randomised, blinded, trial of clopidogrel versus aspirin in patients at risk of ischaemic events (CAPRIE). Lancet. 1996;348(9038):1329-1339.

202. Bennett CL, Connors JM, Carwile JM, et al. Thrombotic thrombocytopenic purpura associated with clopidogrel. N Engl J Med. 2000;342(24):1773-1777.

203. Bhatt DL, Fox KA, Hacke W, et al; CHARISMA Investigators. Clopidogrel and aspirin versus aspirin alone for the prevention of atherothrombotic events. $N$ Engl J Med. 2006;354(16):1706-1717.

204. Chen ZM, Jiang LX, Chen YP, et al; COMMIT (ClOpidogrel and Metoprolol in Myocardial Infarction Trial) collaborative group. Addition of clopidogrel to aspirin in 45,852 patients with acute myocardial infarction: randomised placebocontrolled trial. Lancet. 2005;366(9497):1607-1621.

205. Diener HC, Bogousslavsky J, Brass LM, et al; MATCH investigators. Aspirin and clopidogrel compared with clopidogrel alone after recent ischaemic stroke or transient ischaemic attack in high-risk patients (MATCH): randomised, double-blind, placebo-controlled trial. Lancet. 2004;364(9431):331-337.

206. Sabatine MS, Cannon CP, Gibson CM, et al; CLARITYTIMI 28 Investigators. Addition of clopidogrel to aspirin and fibrinolytic therapy for myocardial infarction with ST-segment elevation. N Engl J Med. 2005;352(12):1179-1189.

207. Steinhubl SR, Berger PB, Mann JT III, et al; CREDO Investigators. Clopidogrel for the Reduction of Events During Observation. Early and sustained dual oral antiplatelet therapy following percutaneous coronary intervention: a randomized controlled trial. JAMA. 2002;288(19): 2411-2420.

208. Yusuf S, Zhao F, Mehta SR, Chrolavicius S, Tognoni G, Fox KK; Clopidogrel in Unstable Angina to Prevent Recurrent Events Trial Investigators. Effects of clopidogrel in addition to aspirin in patients with acute coronary syndromes without ST-segment elevation. N Engl J Med. 2001;345(7): 494-502.

209. Mehta SR, Tanguay JF, Eikelboom JW, et al; CURRENTOASIS 7 trial investigators. Double-dose versus standard- dose clopidogrel and high-dose versus low-dose aspirin in individuals undergoing percutaneous coronary intervention for acute coronary syndromes (CURRENT-OASIS 7): a randomised factorial trial. Lancet. 2010;376(9748):1233-1243.

210. Farid NA, Smith RL, Gillespie TA, et al. The disposition of prasugrel, a novel thienopyridine, in humans. Drug Metab Dispos. 2007;35(7):1096-1104.

211. Brandt JT, Payne CD, Wiviott SD, et al. A comparison of prasugrel and clopidogrel loading doses on platelet function: magnitude of platelet inhibition is related to active metabolite formation. Am Heart J. 2007;153(1):66.e9-16.

212. Jernberg T, Payne CD, Winters KJ, et al. Prasugrel achieves greater inhibition of platelet aggregation and a lower rate of non-responders compared with clopidogrel in aspirintreated patients with stable coronary artery disease. Eur Heart J. 2006;27(10):1166-1173.

213. Farid NA, Payne CD, Ernest CS II, et al. Prasugrel, a new thienopyridine antiplatelet drug, weakly inhibits cytochrome P450 2B6 in humans. J Clin Pharmacol. 2008;48(1):53-59.

214. Wiviott SD, Braunwald E, McCabe CH, et al; TRITONTIMI 38 Investigators. Prasugrel versus clopidogrel in patients with acute coronary syndromes. N Engl J Med. 2007 ; 357(20):2001-2015.

215. Chin CT, Roe MT, Fox KA, et al; TRILOGY ACS Steering Committee. Study design and rationale of a comparison of prasugrel and clopidogrel in medically managed patients with unstable angina/non-ST-segment elevation myocardial infarction: the TaRgeted platelet Inhibition to cLarify the Optimal strateGy to medicallY manage Acute Coronary Syndromes (TRILOGY ACS) trial. Am Heart J. 2010;160(1):16-22.e1.

216. Coller BS, Peerschke EI, Scudder LE, Sullivan CA. A murine monoclonal antibody that completely blocks the binding of fibrinogen to platelets produces a thrombasthenic-like state in normal platelets and binds to glycoproteins IIb and/or IIIa. J Clin Invest. 1983;72(1):325-338.

217. Coller BS. Platelet GPIIb/IIIa antagonists: the first antiintegrin receptor therapeutics. J Clin Invest. 1997;100 (suppl 11):S57-S60.

218. Tcheng JE, Ellis SG, George BS, et al. Pharmacodynamics of chimeric glycoprotein IIb/IIIa integrin antiplatelet antibody Fab 7E3 in high-risk coronary angioplasty. Circulation. 1994;90(4):1757-1764.

219. Mascelli MA, Lance ET, Damaraju L, Wagner CL, Weisman HF, Jordan RE. Pharmacodynamic profile of short-term abciximab treatment demonstrates prolonged platelet inhibition with gradual recovery from GP IIb/IIIa receptor blockade. Circulation. 1998;97(17):1680-1688.

220. The EPIC Investigators. Use of a monoclonal antibody directed against the platelet glycoprotein IIb/IIIa receptor in high-risk coronary angioplasty. N Engl J Med. 1994;330(14):956-961.

221. Tcheng JE, Kereiakes DJ, Lincoff AM, et al. Abciximab readministration: results of the ReoPro Readministration Registry. Circulation. 2001;104(8):870-875.

222. Madan M, Kereiakes DJ, Hermiller JB, et al. Efficacy of abciximab readministration in coronary intervention. Am J Cardiol. 2000;85(4):435-440.

223. Curtis BR, Swyers J, Divgi A, McFarland JG, Aster RH. Thrombocytopenia after second exposure to abciximab is caused by antibodies that recognize abciximab-coated platelets. Blood. 2002;99(6):2054-2059.

224. The EPILOG Investigators. Platelet glycoprotein IIb/IIIa receptor blockade and low-dose heparin during percutaneous coronary revascularization. $N$ Engl J Med. 1997;336(24): $1689-1696$

225. Madan M, Berkowitz SD. Understanding thrombocytopenia and antigenicity with glycoprotein IIb-IIIa inhibitors. Am Heart J. 1999;138(4 pt 2):317-326. 
226. Egbertson MS, Chang CT, Duggan ME, et al. Non-peptide fibrinogen receptor antagonists. 2. Optimization of a tyrosine template as a mimic for Arg-Gly-Asp. J Med Chem. 1994;37(16):2537-2551.

227. Hartman GD, Egbertson MS, Halczenko W, et al. Nonpeptide fibrinogen receptor antagonists. 1. Discovery and design of exosite inhibitors. J Med Chem. 1992;35(24): 4640-4642.

228. Vickers S, Theoharides AD, Arison B, et al. In vitro and in vivo studies on the metabolism of tirofiban. Drug Metab Dispos. 1999;27(11):1360-1366.

229. Kereiakes DJ, Kleiman NS, Ambrose J, et al. Randomized, double-blind, placebo-controlled dose-ranging study of tirofiban (MK-383) platelet IIb/IIIa blockade in high risk patients undergoing coronary angioplasty. J Am Coll Cardiol. 1996;27(3):536-542.

230. Smith BS, Gandhi PJ. Pharmacokinetics and pharmacodynamics of low-molecular-weight heparins and glycoprotein IIb/IIIa receptor antagonists in renal failure. J Thromb Thrombolysis. 2001;11(1):39-48.

231. Januzzi JL Jr, Snapinn SM, DiBattiste PM, Jang IK, Theroux P. Benefits and safety of tirofiban among acute coronary syndrome patients with mild to moderate renal insufficiency: results from the Platelet Receptor Inhibition in Ischemic Syndrome Management in Patients Limited by Unstable Signs and Symptoms (PRISM-PLUS) trial. Circulation. 2002;105(20):2361-2366.

232. Bednar B, Cook JJ, Holahan MA, et al. Fibrinogen receptor antagonist-induced thrombocytopenia in chimpanzee and rhesus monkey associated with preexisting drug-dependent antibodies to platelet glycoprotein IIb/IIIa. Blood. 1999; 94(2):587-599.

233. Bougie DW, Wilker PR, Wuitschick ED, et al. Acute thrombocytopenia after treatment with tirofiban or eptifibatide is associated with antibodies specific for ligand-occupied GPIIb/IIIa. Blood. 2002;100(6):2071-2076.

234. Lele M, Sajid M, Wajih N, Stouffer GA. Eptifibatide and 7E3, but not tirofiban, inhibit alpha(v)beta(3) integrinmediated binding of smooth muscle cells to thrombospondin and prothrombin. Circulation. 2001;104(5):582-587.

235. Scarborough RM, Naughton MA, Teng W, et al. Design of potent and specific integrin antagonists. Peptide antagonists with high specificity for glycoprotein IIb-IIIa. J Biol Chem. 1993;268(2):1066-1073.

236. Phillips DR, Teng W, Arfsten A, et al. Effect of Ca2+ on GP IIb-IIIa interactions with integrilin: enhanced GP IIb-IIIa binding and inhibition of platelet aggregation by reductions in the concentration of ionized calcium in plasma anticoagulated with citrate. Circulation. 1997;96(5):1488-1494.

237. Reddan DN, O’Shea JC, Sarembock IJ, et al. Treatment effects of eptifibatide in planned coronary stent implantation in patients with chronic kidney disease (ESPRIT Trial). Am J Cardiol. 2003;91(1):17-21.

238. Phillips DR, Scarborough RM. Clinical pharmacology of eptifibatide. Am J Cardiol. 1997;80(4A):11B-20B.

239. Li YF, Spencer FA, Becker RC. Comparative efficacy of fibrinogen and platelet supplementation on the in vitro reversibility of competitive glycoprotein IIb/IIIa (alphaIIb/beta3) receptor-directed platelet inhibition. Am Heart J. 2001; 142(2):204-210.

240. The PURSUIT Trial Investigators. Inhibition of platelet glycoprotein IIb/IIIa with eptifibatide in patients with acute coronary syndromes.. N Engl J Med. 1998;339(7):436-443.

241. Rezkalla SH, Hayes JJ, Curtis BR, Aster RH. Eptifibatideinduced acute profound thrombocytopenia presenting as refractory hypotension. Catheter Cardiovasc Interv. 2003; 58(1):76-79.
242. The IMPACT-II Investigators. Randomised placebocontrolled trial of effect of eptifibatide on complications of percutaneous coronary intervention: IMPACT-II. Lancet. 1997;349(9063):1422-1428.

243. O'Shea JC, Hafley GE, Greenberg S, et al; ESPRIT Investigators (Enhanced Suppression of the Platelet IIb/IIIa Receptor with Integrilin Therapy trial). Platelet glycoprotein IIb/IIIa integrin blockade with eptifibatide in coronary stent intervention: the ESPRIT trial: a randomized controlled trial. JAMA. 2001;285(19):2468-2473.

244. ESPRIT Investigators. Novel dosing regimen of eptifibatide in planned coronary stent implantation (ESPRIT): a randomised, placebo-controlled trial. Lancet. 2000;356(9247):2037-2044.

245. Effects of platelet glycoprotein IIb/IIIa blockade with tirofiban on adverse cardiac events in patients with unstable angina or acute myocardial infarction undergoing coronary angioplasty. The RESTORE Investigators. Randomized Efficacy Study of Tirofiban for Outcomes and REstenosis. Circulation. 1997;96(5):1445-1453.

246. The CAPTURE Investigators. Randomised placebocontrolled trial of abciximab before and during coronary intervention in refractory unstable angina: the CAPTURE Study. Lancet. 1997;349(9063):1429-1435.

247. EPISTENT Investigators. Randomised placebo-controlled and balloon-angioplasty-controlled trial to assess safety of coronary stenting with use of platelet glycoprotein-IIb/IIIa blockade. Lancet. 1998;352(9122):87-92

248. Topol EJ, Lincoff AM, Kereiakes DJ, et al. Multi-year follow-up of abciximab therapy in three randomized, placebocontrolled trials of percutaneous coronary revascularization. Am J Med. 2002;113(1):1-6.

249. Stone GW, Grines CL, Cox DA, et al; Controlled Abciximab and Device Investigation to Lower Late Angioplasty Complications (CADILLAC) Investigators. Comparison of angioplasty with stenting, with or without abciximab, in acute myocardial infarction. N Engl J Med. 2002;346(13):957-966.

250. Moliterno DJ, Yakubov SJ, DiBattiste PM, et al; TARGET investigators. Outcomes at 6 months for the direct comparison of tirofiban and abciximab during percutaneous coronary revascularisation with stent placement: the TARGET follow-up study. Lancet. 2002;360(9330):355-360.

251. Topol EJ, Moliterno DJ, Herrmann HC, et al; TARGET Investigators. Do Tirofiban and ReoPro Give Similar Efficacy Trial. Comparison of two platelet glycoprotein IIb/IIIa inhibitors, tirofiban and abciximab, for the prevention of ischemic events with percutaneous coronary revascularization. N Engl J Med. 2001;344(25):1888-1894.

252. Hausleiter J, Kastrati A, Mehilli J, et al; ISAR-SMART-2 Investigators. A randomized trial comparing phosphorylcholine-coated stenting with balloon angioplasty as well as abciximab with placebo for restenosis reduction in small coronary arteries. J Intern Med. 2004;256(5):388-397.

253. Kastrati A, Mehilli J, Neumann FJ, et al; Intracoronary Stenting and Antithrombotic: Regimen Rapid Early Action for Coronary Treatment 2 (ISAR-REACT 2) Trial Investigators. Abciximab in patients with acute coronary syndromes undergoing percutaneous coronary intervention after clopidogrel pretreatment: the ISAR-REACT 2 randomized trial. JAMA. 2006;295(13):1531-1538.

254. Kastrati A, Mehilli J, Schühlen H, et al; Intracoronary Stenting and Antithrombotic Regimen-Rapid Early Action for Coronary Treatment Study Investigators. A clinical trial of abciximab in elective percutaneous coronary intervention after pretreatment with clopidogrel. N Engl J Med. 2004; 350(3):232-238.

255. Mehilli J, Kastrati A, Schühlen $\mathrm{H}$, et al; Intracoronary Stenting and Antithrombotic Regimen: Is Abciximab a 
Superior Way to Eliminate Elevated Thrombotic Risk in Diabetics (ISAR-SWEET) Study Investigators. Randomized clinical trial of abciximab in diabetic patients undergoing elective percutaneous coronary interventions after treatment with a high loading dose of clopidogrel. Circulation. 2004;110(24):3627-3635.

256. Simoons ML; GUSTO IV-ACS Investigators. Effect of glycoprotein IIb/IIIa receptor blocker abciximab on outcome in patients with acute coronary syndromes without early coronary revascularisation: the GUSTO IV-ACS randomised trial. Lancet. 2001;357(9272):1915-1924.

257. Platelet Receptor Inhibition in Ischemic Syndrome Management (PRISM) Study Investigators. A comparison of aspirin plus tirofiban with aspirin plus heparin for unstable angina. N Engl J Med. 1998;338(21):1498-1505.

258. Platelet Receptor Inhibition in Ischemic Syndrome Management in Patients Limited by Unstable Signs and Symptoms (PRISM-PLUS) Study Investigators. Inhibition of the platelet glycoprotein IIb/IIIa receptor with tirofiban in unstable angina and non-Q-wave myocardial infarction. $N$ Engl J Med. 1998;338(21):1488-1497.

259. Investigators TP. Randomized trial of potent platelet IIb/IIIa antagonism, heparin, or both in patients with unstable angina: the PARAGON study [abstract]. Circulation. 1996; 94:I-553.

260. Boersma E, Harrington RA, Moliterno DJ, White H, Simoons ML. Platelet glycoprotein IIb/IIIa inhibitors in acute coronary syndromes. Lancet. 2002;360(9329):342-343.

261. Lincoff AM, Califf RM, Van de Werf F, et al; Global Use of Strategies To Open Coronary Arteries Investigators (GUSTO). Mortality at 1 year with combination platelet glycoprotein IIb/IIIa inhibition and reduced-dose fibrino- lytic therapy vs conventional fibrinolytic therapy for acute myocardial infarction: GUSTO V randomized trial. JAMA. 2002;288(17):2130-2135.

262. Stone GW, Witzenbichler B, Guagliumi G, et al; HORIZONS-AMI Trial Investigators. Bivalirudin during primary PCI in acute myocardial infarction. $N$ Engl $\mathrm{J} \mathrm{Med.}$ 2008;358(21):2218-2230.

263. Mehilli J, Kastrati A, Schulz S, et al; Bavarian Reperfusion Alternatives Evaluation-3 (BRAVE-3) Study Investigators. Abciximab in patients with acute ST-segment-elevation myocardial infarction undergoing primary percutaneous coronary intervention after clopidogrel loading: a randomized double-blind trial. Circulation. 2009;119(14):1933-1940.

264. De Luca G, Navarese E, Marino P. Risk profile and benefits from Gp IIb-IIIa inhibitors among patients with ST-segment elevation myocardial infarction treated with primary angioplasty: a meta-regression analysis of randomized trials. Eur Heart J. 2009;30(22):2705-2713.

265. Abciximab Emergent Stroke Treatment Trial (AbESTT) Investigators. Emergency administration of abciximab for treatment of patients with acute ischemic stroke: results of a randomized phase 2 trial. Stroke. 2005;36(4):880-890.

266. Adams HP Jr, Effron MB, Torner J, et al; AbESTT-II Investigators. Emergency administration of abciximab for treatment of patients with acute ischemic stroke: results of an international phase III trial: Abciximab in Emergency Treatment of Stroke Trial (AbESTT-II). Stroke. 2008;39(1): 87-99.

267. Pancioli AM, Broderick J, Brott T, et al; CLEAR Trial Investigators. The combined approach to lysis utilizing eptifibatide and rt-PA in acute ischemic stroke: the CLEAR stroke trial. Stroke. 2008;39(12):3268-3276. 